\title{
Recrystallization-mediated crack initiation in tungsten under simultaneous high-flux hydrogen plasma loads and high-cycle transient heating
}

\section{Citation for published version (APA):}

Li, Y., Morgan, T. W., Vermeij, T., Vernimmen, J. W. M., Loewenhoff, T., Hoefnagels, J. P. M., van Dommelen, J. A. W., Wirtz, M., De Temmerman, G., Verbeken, K., \& Geers, M. G. D. (2021). Recrystallization-mediated crack initiation in tungsten under simultaneous high-flux hydrogen plasma loads and high-cycle transient heating. Nuclear Fusion, 61(4), [046018]. https://doi.org/10.1088/1741-4326/abe312

\section{Document license:}

TAVERNE

DOI:

10.1088/1741-4326/abe312

Document status and date:

Published: 01/04/2021

\section{Document Version:}

Publisher's PDF, also known as Version of Record (includes final page, issue and volume numbers)

\section{Please check the document version of this publication:}

- A submitted manuscript is the version of the article upon submission and before peer-review. There can be important differences between the submitted version and the official published version of record. People interested in the research are advised to contact the author for the final version of the publication, or visit the DOI to the publisher's website.

- The final author version and the galley proof are versions of the publication after peer review.

- The final published version features the final layout of the paper including the volume, issue and page numbers.

Link to publication

\footnotetext{
General rights

- You may freely distribute the URL identifying the publication in the public portal. follow below link for the End User Agreement:

www.tue.nl/taverne

\section{Take down policy}

If you believe that this document breaches copyright please contact us at:

openaccess@tue.nl

providing details and we will investigate your claim.
}

Copyright and moral rights for the publications made accessible in the public portal are retained by the authors and/or other copyright owners and it is a condition of accessing publications that users recognise and abide by the legal requirements associated with these rights.

- Users may download and print one copy of any publication from the public portal for the purpose of private study or research.

- You may not further distribute the material or use it for any profit-making activity or commercial gain

If the publication is distributed under the terms of Article 25fa of the Dutch Copyright Act, indicated by the "Taverne" license above, please 


\section{(6) nuclear IAEA fusIOn}

\section{PAPER}

Recrystallization-mediated crack initiation in tungsten under simultaneous high-flux hydrogen plasma loads and high-cycle transient heating

To cite this article: Y. Li et al 2021 Nucl. Fusion 61046018

View the article online for updates and enhancements.

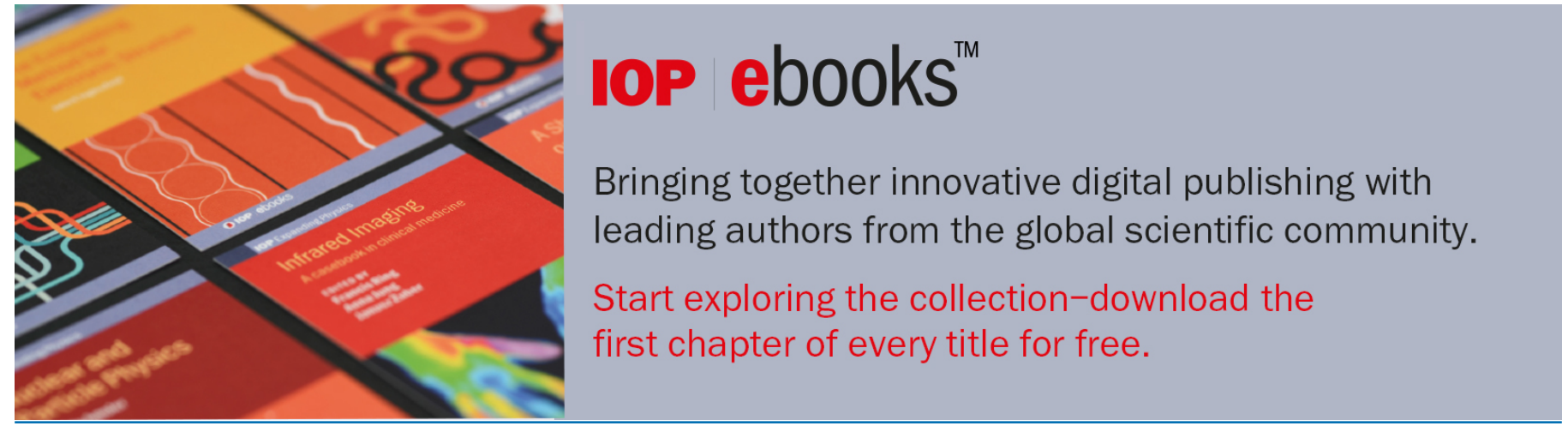

This content was downloaded from IP address 131.155 .98 .160 on $04 / 08 / 2021$ at 07:37 


\title{
Recrystallization-mediated crack initiation in tungsten under simultaneous high-flux hydrogen plasma loads and high-cycle transient heating
}

\author{
Y. Li ${ }^{1,2,3, *}$, T.W. Morgan ${ }^{1} \oplus$, T. Vermeij ${ }^{2}$, J.W.M. Vernimmen ${ }^{1}$, \\ Th. Loewenhoff ${ }^{4}\left({ }^{\circ}\right.$, J.P.M. Hoefnagels ${ }^{2}{ }^{\circ}$, J.A.W. van Dommelen ${ }^{2}{ }^{\circ}$, \\ M. Wirtz ${ }^{4}$, G. De Temmerman ${ }^{5}$,, K. Verbeken ${ }^{3}$ and M.G.D. Geers ${ }^{2}$ \\ ${ }^{1}$ DIFFER-Dutch Institute for Fundamental Energy Research, De Zaale 20, 5612 AJ Eindhoven, \\ Netherlands \\ 2 Department of Mechanical Engineering, Eindhoven University of Technology, P.O. Box 5135600 MB, \\ Eindhoven, Netherlands \\ 3 Department of Materials, Textiles and Chemical Engineering, Ghent University (UGent), \\ Technologiepark 46, B-9052, Ghent, Belgium \\ ${ }^{4}$ Forschungszentrum Jülich, Institut für Energie- und Klimaforschung, 52425, Jülich, Germany \\ 5 ITER Organization, Route de Vinon sur Verdon, CS 90 046, 13067 St Paul Lez Durance Cedex, France \\ E-mail: Y.Li@differ.nl
}

Received 10 December 2020, revised 22 January 2021

Accepted for publication 4 February 2021

Published 12 March 2021

\begin{abstract}
Tungsten and tungsten-based alloys are the leading material choices for the divertor plasma facing components (PFCs) in future fusion reactors. Recrystallization may occur when they undergo high heat loads, drastically modifying the predesigned grain structures and the associated desired mechanical properties. However, the influence of recrystallization on the thermal fatigue behavior of tungsten PFCs still remains unclear. In this study, ITER-grade tungsten was simultaneously exposed to a high-flux hydrogen plasma $\left(\sim 5 \times 10^{24} \mathrm{~m}^{-2} \mathrm{~s}^{-1}\right)$ and high-cycle $\left(10^{4}-10^{5}\right)$ transient heat loads in the linear plasma device Magnum-PSI. By correlating the surface temperature distribution, obtained by analyzing temperature-, wavelength-, and surface-dependent emissivity, and the surface modifications of the plasma exposed specimens, the crack initiation heat flux factor threshold was found to be

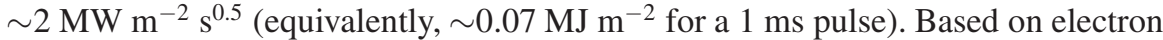
backscatter diffraction analyses of cross-sections near the crack initiation sites, faster recrystallization kinetics near the surface compared to literature was observed and the surface cracks preferentially initiated at high angle grains boundaries (HAGBs). Upon recrystallization, the yield strength decreases which entails increasing cyclic plastic strains. The HAGBs fraction is increased, which constrains the transfer of plastic strains at grain boundaries. The recrystallization decreases the dislocation density, which promotes heterogeneous deformation. All these mechanisms explain the reduced crack initiation threshold of recrystallized tungsten compared to its as-received counterpart. The results provide new insights into the structural failure mechanisms in tungsten PFCs exposed to extreme fusion plasmas.
\end{abstract}

* Author to whom any correspondence should be addressed 
Keywords: PFCs, tungsten recrystallization, thermal fatigue, hydrogen plasma, edge localized modes (ELMs), EBSD

(Some figures may appear in colour only in the online journal)

\section{Introduction}

The power handling capability of tungsten plasma facing components (PFCs) constrains the operating space of future nuclear fusion reactors. It is thus imperative to identify tungsten's power handling limits under divertor-relevant plasma conditions, where the steady-state and transient heat loads constitute two primary structural damage driving forces. The maximum tolerable steady-state heat flux is often mentioned to be $10 \mathrm{MW} \mathrm{m}{ }^{-2}$ [1-3]. ${ }^{6}$ It has been recently demonstrated that the ITER monoblock (MB) technology, in this case a PFC mockup provided by the 'Fusion for Energy', can withstand high-flux steady-state deuterium plasmas in MagnumPSI with an accumulated fluence comparable to one year of ITER fusion power operation ${ }^{7}$ without structural failure [4]. The peak heat flux of the plasma beam (Gaussian distribu-

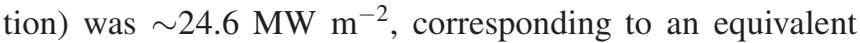
uniform heat flux of $\sim 13 \mathrm{MW} \mathrm{m}^{-2}$ which would produce the same surface temperature $(\sim 1850 \mathrm{~K})$ in ITER. Among the observed microstructural modifications, recrystallization is an important one, extending $\sim 2 \mathrm{~mm}$ into the bulk material. Coincidentally, a numerical study using the ITER MB geometry [5], suggests that deep cracking would occur in the MB once a depth of about $2 \mathrm{~mm}$ of tungsten underwent full recrystallization under a ' 300 cycles at $20 \mathrm{MW} \mathrm{m}^{-2}$, thermal loading condition (motivated by the observation of selfcastellation in some MBs in footnote 6). To limit the recrystallized surface layer to $2 \mathrm{~mm}$, during the required operational lifetime of the divertor, and assuming the recrystallization kinetics of deformed tungsten from [6], the stationary power handling capability of the MB may be extended to $\sim 16 \pm$ $2.5 \mathrm{MW} \mathrm{m}^{-2}$ as a guideline for ITER operation [7]. Here, the role played by recrystallization in determining the steadystate power handling capability of tungsten MBs is important. Recrystallization has also been shown to have an important influence on the severity of transient heating damage, which is an undesirable consequence of plasma instabilities such as type-I edge localized modes (ELMs) [8, 9]. The transient heating creates surface cracks, which can grow deeper into the bulk under steady-state heat loads inducing tensile stresses [10]. It therefore poses a serious threat to the component's structural integrity of the ITER divertor, thereby motivating

\footnotetext{
${ }^{6}$ The qualification program consisted of 5000 cycles at $10 \mathrm{MW} \mathrm{m}^{-2}$ and 300 cycles at $20 \mathrm{MW} \mathrm{m}^{-2}$ stationary heat loads (typically $10 \mathrm{~s}$ on and $10 \mathrm{~s}$ off). It was found that self-castellation (macroscopic cracks along the coolant axis and perpendicular to loaded surface) never appeared after the 5000 cycles at $10 \mathrm{MW} \mathrm{m}^{-2}$ loading but appeared in some cases during $20 \mathrm{MW} \mathrm{m}^{-2}$ loading [3].

${ }^{7}$ The test did not cycle the heat flux like that in footnote 6 .
}

extensive ongoing studies [11-16]. Until now, the fatigue crack initiation heat flux factor threshold for the transients was identified to be $\sim 6 \mathrm{MW} \mathrm{m}{ }^{-2} \mathrm{~s}^{0.5}$ for double forged tungsten with the elongated grains oriented parallel to the heat-loaded surface. This value was obtained using an electron beam facility at a base surface temperature of $973 \mathrm{~K}$ and a pulse number of $10^{5}$ [17]. Intriguingly, when fully recrystallized tungsten (after $1873 \mathrm{~K}$ for $1 \mathrm{~h}$ ) was tested under the same loading condition, the crack initiation heat flux factor threshold dropped to $\sim 3 \mathrm{MW} \mathrm{m}^{-2} \mathrm{~s}^{0.5}[18]$. The tungsten PFCs may face simultaneous steady-state and transient particle/heat loadings in ITER if full ELM suppression is not achieved, entering a surface temperature regime triggering recrystallization. Hence, the crack initiation behavior of tungsten with an evolving microstructure induced by recrystallization, remains to be investigated in greater depth.

Accompanied by drastic changes in microstructure and mechanical properties in most metals and metallic alloys, recrystallization surely affects the fracture behavior of tungsten. Through three-point bending tests of recrystallized tungsten, a reduced ductility (described by the strain-to-failure) was registered, which was attributed to the diminished fraction of low angle grain boundaries (LAGBs) and a reduced density of edge dislocations [19]. However, in some studies, improved ductility after recrystallization has been observed, e.g. in tensile tests of pure tungsten $[20,21]$. Moreover, in the case of cyclic thermal loading, the yield stress instead of the ductility is a more relevant measure to assess the susceptibility to crack initiation. As suggested by the Manson-Coffin relationship [22, 23], which formulates the fatigue life of an unnotched specimen under uniaxial tension/compression plastic straining as a function of the plastic strain amplitude, a lower yield strength (after recrystallization) would result in a higher plastic strain per cycle and consequently a reduced fatigue life. This relationship was adopted in the numerical work in reference [5] and later in reference [24] to conclude that the recrystallization depth in a tungsten $\mathrm{MB}$ is the prime factor that influences macro-cracking. A simultaneous steady-state and transient heat load, however, presents a more complex loading condition than those considered in previous related studies, which may affect the validity of the assumed mechanisms. A detailed microstructural survey to reveal the role of recrystallization in crack initiation under such combined loading conditions remains a mandatory task, considering the contradicting experimental observations and empirical assumptions used in numerical studies.

The recrystallization kinetics of tungsten can be more complicated under divertor plasma conditions than under conventional heat treatments. Helium plasma exposure has been 
reported to retard the recrystallization of tungsten $[25,26]$ compared to literature $[6,27,28]$. Moreover, it is known that plastic strain also constitutes a driving force for grain boundary migration $[29,30]$. Experimentally, abnormal grain growth has been reported for molybdenum during high-temperature tensile tests [31], for copper subjected to cyclic heat treatments [32], and for tungsten exposed to 5000 thermal cycles at $10 \mathrm{MW} \mathrm{m}^{-2}$ and 1000 thermal cycles at $20 \mathrm{MW} \mathrm{m}^{-2}$ [33]. Whether the recrystallization kinetics of tungsten is accelerated or retarded when exposed to simultaneous steady-state and transient particle/heat loadings, remains to be clarified.

This study aims to explore the coupled problems outlined above. The following approach was thereby adopted. First, a combined steady-state/transient loading was applied in the Magnum-PSI linear plasma device where the steadystate high-flux hydrogen plasma maintained the tungsten targets close to their recrystallization temperature $(\sim 1550 \mathrm{~K})$, while the repetitive transient heating by a high-power laser with up to $10^{5}$ pulses induced surface cracks. Thereafter, by mapping the surface modifications and the in situ monitored temperature fields, the crack initiation threshold was identified. The effects of recrystallization were studied based on detailed microstructural analyses of cross-sections in the neighborhood of the crack initiation sites. The main innovative outcomes of this study are: (a) unique ITERrelevant particle and heat loading of tungsten using the linear plasma device Magnum-PSI; (b) numerical-experimental thermal analyses combining in situ infra-red thermography measurements (accounting for temperature-, wavelength-, and surface-dependent emissivity), with finite element modeling; (c) systematic post-mortem microstructural characterizations, containing detailed electron backscatter diffraction (EBSD) mapping, macro-indentation and scanning electron microscope (SEM) fracture analyses.

The paper is structured as follows. In section 2, the experimental procedure including plasma exposure and in situ and post-mortem diagnostics is detailed. Section 3 maps the sample surface modifications after plasma exposure to their temperature fields to determine the crack initiation threshold. In section 4 , the crystallographic orientation data obtained on meticulously prepared cross-sections near the crack initiation sites are analyzed, allowing to rationalize the observed results on recrystallization-mediated fatigue crack initiation.

\section{Experimental methodology}

\subsection{Plasma exposure}

Polycrystalline samples $\left(20 \times 20 \times 3 \mathrm{~mm}^{3}\right)$ were cut from a forged pure tungsten rod fabricated by Plansee ${ }^{\circledR}$. The samples were prepared with a standard metallographic procedure (described in [10]) and then exposed in the linear plasma generator Magnum-PSI [34], which is sketched in figure 1(a). Typical top-view (i.e. plasma-facing) and cross-section view scanning electron micrographs of the samples before plasma exposure are illustrated in figures $1(b)$ and $(c)$, respectively. The longitudinal direction of the grains, see figure 1(c), is oriented perpendicular to the heat-loaded surface plane, which is consistent with the ITER specifications (hereafter referred to as ITER-grade). The samples were clamped to a watercooled copper holder with one GRAFOIL ${ }^{\circledR}$ thermal contact layer in between using a titanium-zirconium-molybdenum alloy clamping ring.

The steady-state hydrogen plasma was generated by a cascaded arc source using a direct current of $160 \mathrm{~A}$ and an $\mathrm{H}_{2}$ gas flow of $\sim 8.0 \mathrm{~Pa} \cdot \mathrm{m}^{3} \mathrm{~s}^{-1}$, delivered to the targets by applying a constant axial magnetic field of $1.2 \mathrm{~T}$, see reference [34] for details. The plasma beam had a Gaussian profile with a fullwidth half-maximum (FWHM) of $\sim 10 \mathrm{~mm}$. The samples were electrically isolated during plasma exposure. Transient heating was applied using a $1064 \mathrm{~nm} \mathrm{Nd:YAG} \mathrm{laser} \mathrm{(LASAG} \mathrm{FLS}$ $352-302$ ) with a pulse duration of $1 \mathrm{~ms}$ and a $10 \mathrm{~Hz}$ repetition rate. The laser has a Gaussian spatial profile (FWHM $\sim 4 \mathrm{~mm}$ ) and a nearly square wave temporal profile. With an angle of incidence of $\sim 51^{\circ}$, the projected laser spot on the target is elliptical, with an area of $\sim 6.4 \times 4 \mathrm{~mm}^{2}$.

\subsection{In situ diagnostics}

The electron temperature $\left(T_{\mathrm{e}}\right)$ and density $\left(n_{\mathrm{e}}\right)$ of the hydrogen plasma were measured by TS $\sim 30 \mathrm{~mm}$ in front of the target [35]. For the hydrogen plasma in Magnum-PSI, collective TS measurements revealed that the ion temperature is close to the electron temperature [36]. This conclusion was used to calculate the steady-state heat flux using the Bohm sheath theory [10]. Likewise, the ion impact energy to the surface on the center of the plasma beam was calculated to be $\sim 10 \mathrm{eV}$.

Two methods were used to monitor the surface temperature of the targets during plasma exposure. Targeting the laser spot center, a multi-wavelength pyrometer (FAR Associates ${ }^{\circledR}$ FMPI) recorded the surface temperature in the spectral range of 1.1-1.7 $\mu \mathrm{m}$ without prior knowledge of the emissivity of tungsten. In [11], it is demonstrated that an adequate accuracy is achieved by the pyrometer regardless of the strong hydrogen absorption and emission lines. The 2D surface temperature profile was monitored by a fast-framing infra-red camera (IR-cam) (FLIR ${ }^{\circledR}$ SC7500MB) in the wavelength range of 3.97-4.01 $\mu \mathrm{m}$ and at a frequency of $\sim 5 \mathrm{kHz}$. The spatial resolution at the specimen surface was approximately $300 \mu \mathrm{m}$. It was verified that no hydrogen emission line was present in the spectral range of the IR-cam; the measured intensity therefore reflected the temperature of the target [11].

Table 1 summarizes the experimental conditions. The plasma parameters refer to the beam center, whereas the base surface temperature $T_{\text {base }}$ and peak $\Delta T$ indicate the values measured at the laser spot center with a pyrometer and an IRcam. $T_{\text {base }}$ results from the steady-state hydrogen plasma. Note that the laser spot center was typically spaced 1-2 mm off the plasma beam center during the experiments, which was accounted for throughout all the analyses. For the specimen's nomenclature: IG refers to ITER-grade and RX refers to recrystallization. Their initial microstructures are shown in figures $1(b)$ and $(c)$ and $11(d)$, respectively. The uncertainty in ion flux and steady-state heat flux comes from the 


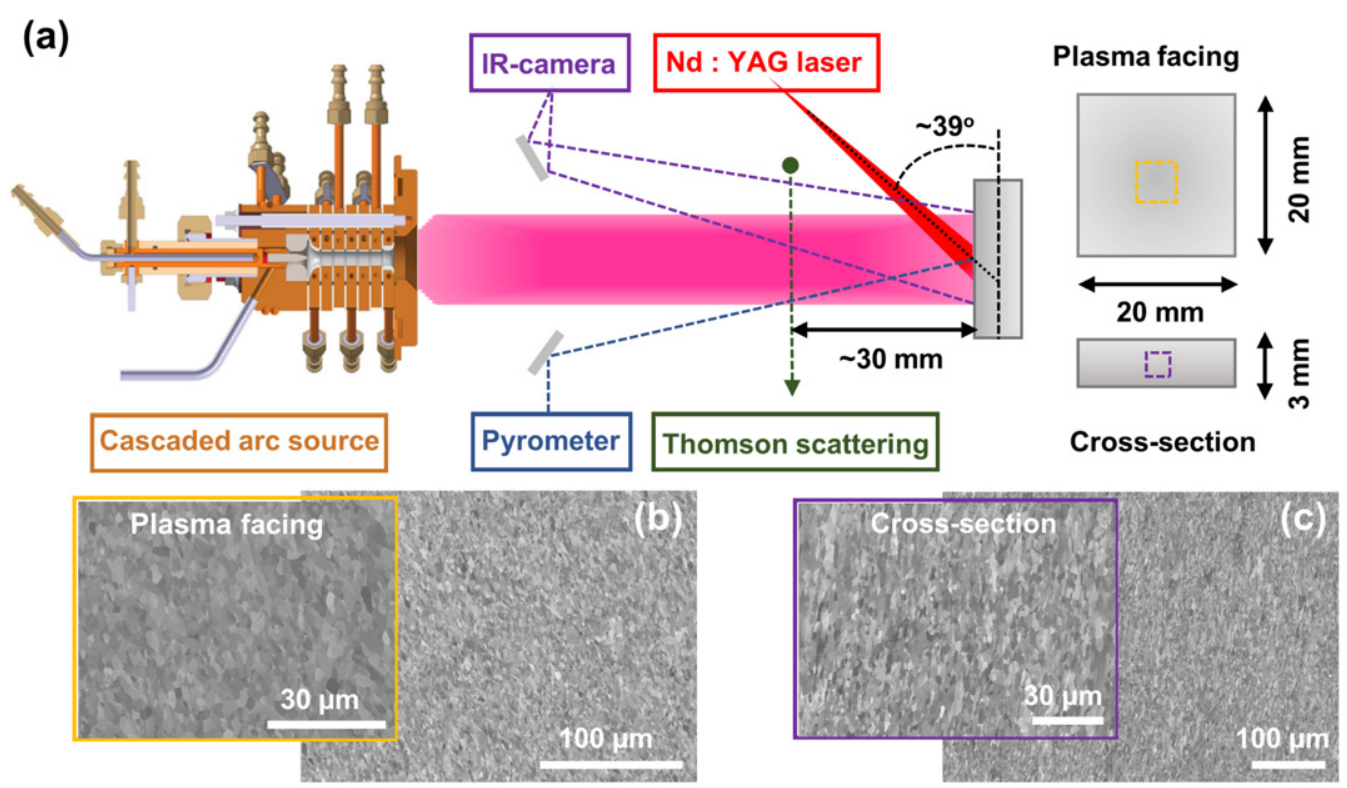

Figure 1. Schematic overview of the experimental setup. (a) The steady-state hydrogen plasma is generated by a cascaded arc source (left), directed to a water-cooled tungsten target by a strong axial magnetic field. The transient heating is applied by an Nd:YAG laser, with an incident angle of $\sim 51^{\circ}$. The electron temperature and density of the plasma are measured by Thomson scattering (TS) $\sim 30 \mathrm{~mm}$ in front of the target. The surface temperature of the sample is monitored by a pyrometer, which is directed towards the laser spot center, and a fast-framing IR-cam, registering the 2D surface temperature field. Representative $(b)$ top-view and $(c)$ cross-sectional view micrographs of the samples.

Table 1. Loading conditions in this study. The ion flux and steady-state heat flux are calculated from the Bohm sheath theory using the measured TS data. The base surface temperature $T_{\text {base }}$ is measured by a pyrometer at the laser spot center. The peak temperature excursion $(\Delta T)$ induced by a laser is recorded by an IR-cam, here tabulated only at the beginning of the exposure. Its time evolution is displayed in figure 7 .

\begin{tabular}{lccccc}
\hline Specimen & $\begin{array}{c}\text { Peak ion } \\
\text { flux }\left(\times 10^{24} \mathrm{~m}^{-2} \mathrm{~s}^{-1}\right)\end{array}$ & $\begin{array}{c}\text { Peak steady-state heat } \\
\text { flux }\left(\mathrm{MW} \mathrm{m}^{-2}\right)\end{array}$ & $T_{\text {base }}(\mathrm{K})$ & Peak $\Delta T(\mathrm{~K})$ & Pulses (\#) \\
\hline IG\#1 & & $1571 \pm 11$ & & $1 \times 10^{4}$ \\
IG\#2 & & $1583 \pm 12$ & & $3 \times 10^{4}$ \\
IG\#3 & $4.75 \pm 0.3$ & $16.47 \pm 1$ & $1573 \pm 11$ & $\sim 70 \pm 3$ & $6 \times 10^{4}$ \\
IG\#4 & & & $1552 \pm 10$ & & $10^{5}$ \\
IG\#5 & $3.79 \pm 0.2$ & $13.01 \pm 0.8$ & $1005 \pm 5$ & $195 \pm 3$ & \\
RX & & & & &
\end{tabular}

instrumental uncertainty of the TS system. The uncertainty in $T_{\text {base }}$ originates from the finite spot size of the pyrometer and the uncertainty in $\Delta T$ is one standard deviation from averaging 20 pulses

\subsection{Post-mortem characterization}

The surface morphology was analyzed using a (SEM, Tescan Mira $3{ }^{\circledR}$ and Phenom Pharos ${ }^{\circledR}$ ). To facilitate the analyses, an array of surface indents, spaced by $100 \mu \mathrm{m}$, were placed using a micro indentation instrument $\left(\mathrm{CSM}^{\circledR}\right)$ as markers across the laser spot boundary on each specimen after plasma exposure. After characterizing the surface morphologies near the indents, cross-sections adjacent to the indents of sample IG\#2, IG\#3, and IG\#4 were metallographically prepared for further investigation. To this end, each sample was first cut by a diamond blade $\sim 1-2 \mathrm{~mm}$ close to the intended cross-section plane. Then the extra material was removed by grinding with finer and finer sandpapers. When the desired cross-section plane was approached within $100 \mu \mathrm{m}$, intermittent manual grinding steps and SEM analyses were applied to reach the desired plane with a few micrometers accuracy. Finally, the crosssection surface was polished with a $3 \mu \mathrm{m}$ diamond suspension and finalized with electro-polishing [10]. By comparing the surface cracks near the indents before and after cross-section preparation, it was confirmed that no artifacts were introduced by the cross-section preparation.

To identify the crystallographic texture and grain maps, EBSD analyses were performed on the cross-section planes using a Tescan Mira3 ${ }^{\circledR}$ SEM equipped with an EDAX DigiView2 ${ }^{\circledR}$ EBSD camera. The acceleration voltage was 20 $\mathrm{kV}$ and the scanning step size was $0.2 \mu \mathrm{m}$. The MTEX toolbox [37] was used to post-process the EBSD data. EBSD datapoints with a so-called 'confidence index' below 0.1 were discarded and no cleaning and smoothing was performed on the EBSD data. Boundaries with misorientations above $2^{\circ}$ 

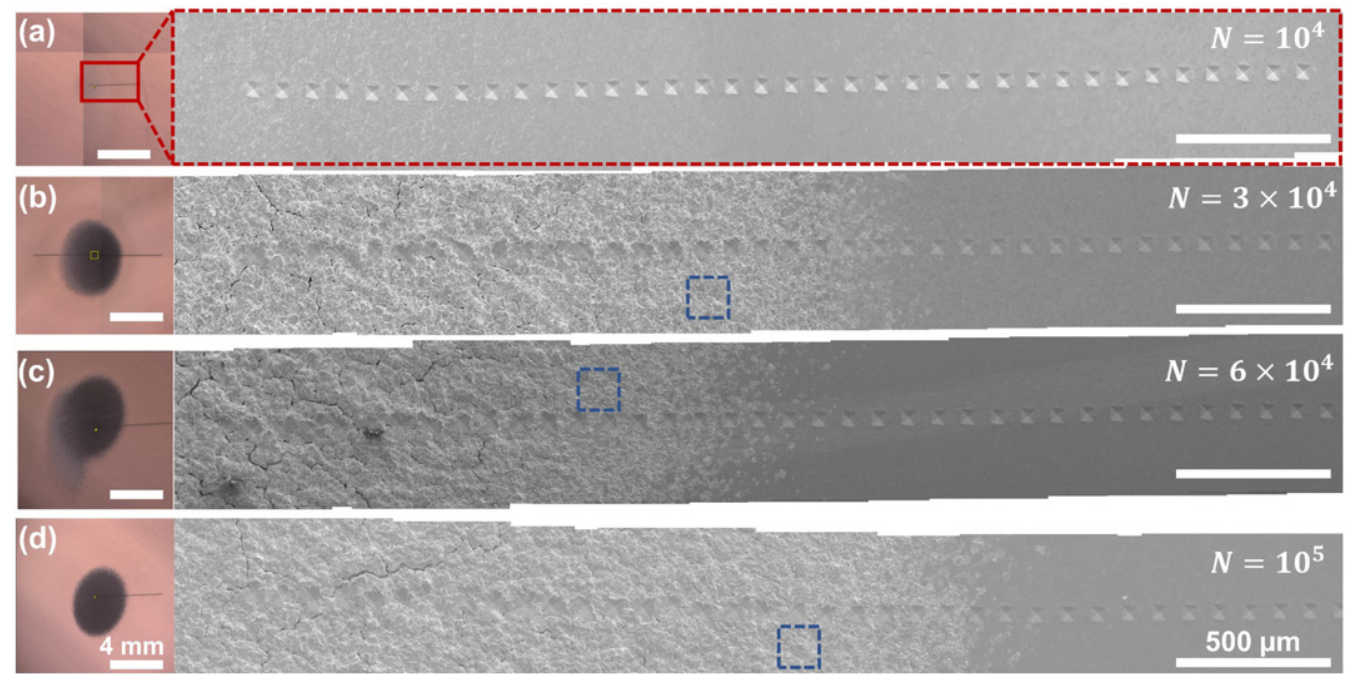

Figure 2. Surface morphologies of the exposed samples. The four images on the left are stitched optical microscopy images whereas on the right stitched secondary electron images are shown. $(a)-(d)$ are sample IG\#1, IG\#2, IG\#3, and IG\#4, respectively, with their transient heating cycles $(N)$ indicated. The blue boxes highlight the cracks that are farthest away from the laser spot, which are shown in larger detail in figure 3. These cracks just passed the threshold to initiate them.
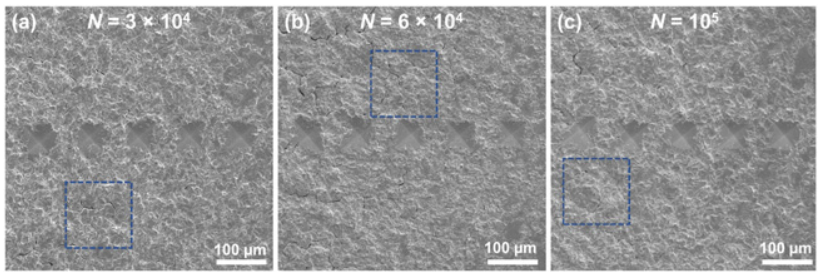

Figure 3. Magnified micrographs of the highlighted cracks in figures $2(b)-(d)$, respectively.

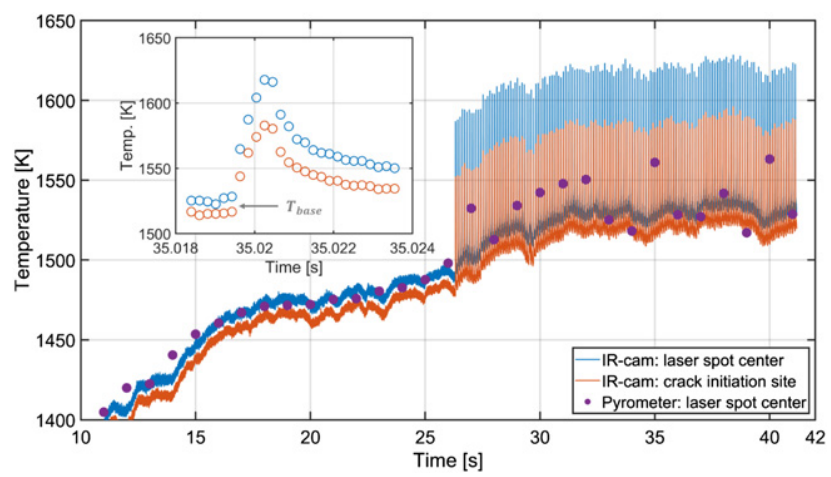

Figure 4. Temperature evolution of sample IG\#4. The starting $10 \mathrm{~s}$ recording is not shown for clarity. $T_{\text {base }}$ results from the steady-state hydrogen plasma, as indicated in the inset. A zoom of one single heat pulse at two pixels near $35 \mathrm{~s}$ is shown in the inset.

were marked as grain boundaries [38] during the grain reconstruction analysis. Additionally, following the convention in reference [39], boundaries with misorientations between $2^{\circ}$ and $15^{\circ}$ were defined as LAGBs, whereas those with a misorientation $>15^{\circ}$ were marked as high angle grain boundaries (HAGBs).
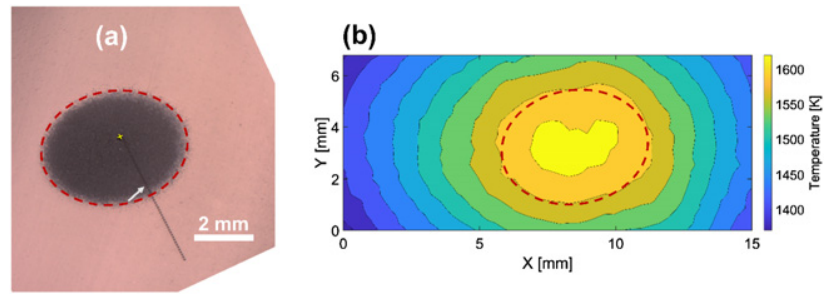

Figure 5. (a) Surface optical image of sample IG\#4. (b) The corresponding peak temperature distribution. The white arrow in (a) marks the crack that was initiated just above the initiation threshold. The black dotted line denotes the indentation array. The oval in $(a)$ is translated to $(b)$, showing a good agreement with a single temperature contour line.

\section{Results}

\subsection{Surface modifications}

Figure 2 shows the stitched SEM micrographs of the exposed specimens along with overview optical microscopy images on the left and the corresponding transient heating cycle $(N)$ at the top-right corner. A clear dark spot induced by the laser is visible in the optical images (left, not in real color), except in sample IG\#1. When zooming in, sample IG\#1 does not show any surface cracks, but the other samples developed crack networks radially outward. In order to assess crack initiation, we focus on the last cracks that appeared which are located at the furthest end from the laser spot, as highlighted with a blue square box in figure 2 , and later magnified in figure 3 . These cracks just passed the threshold to initiate them. In figure 3 some isolated cracks are slightly farther than those highlighted in the blue boxes. Because such cracks are invisible on the cross-section planes for further analysis, they are not considered as crack initiation sites. This nuance is not expected 


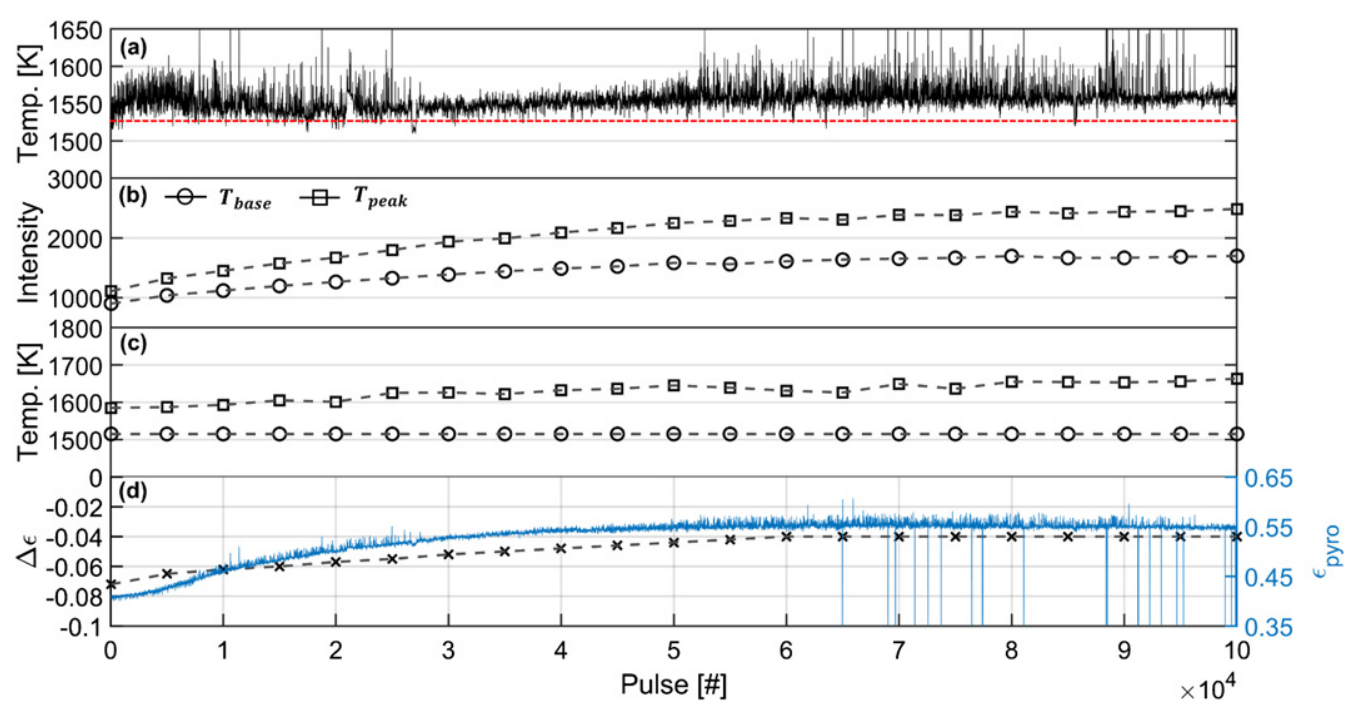

Figure 6. The long-term surface temperature evolution of sample IG\#4 ( $2.8 \mathrm{~h})$. (a) Pyrometer temperature signal with the red line indicating the base surface temperature of the target at the laser spot center. $(b)$ The measured digital counts at the crack initiation site by the IR-cam of every 5000 pulses. (c) The converted temperature after applying emissivity corrections in the left $y$-axis of $(d)$; the right $y$-axis of (d) displays the automatically determined emissivity by the pyrometer at a different wavelength.

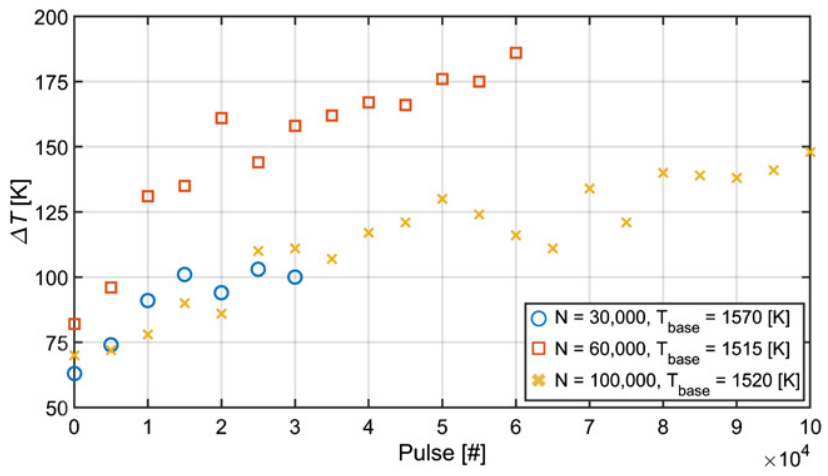

Figure 7. $\Delta T$ evolution of specimen IG\#2, IG\#3, and IG\#4, respectively.

to influence the conclusions of this study. Note that because the analyzed surface paths (indentation arrays) do not share the same positions relative to the respective laser spot, the positions of the blue boxes should not be overinterpreted. By image correlation of the surface modifications and temperature fields, an accurate temperature history at the blue boxes will be deduced in the next section.

\subsection{Thermal analysis}

3.2.1. Surface temperature mapping. The $2 \mathrm{D}$ surface temperature distribution of the target was derived from the measured infrared radiation, as detailed in appendix A. Figure 4 shows the surface temperature evolution of specimen IG\#4 at the beginning of the plasma exposure. At time $\sim 26 \mathrm{~s}$, the laser was triggered, inducing a transient heating $\Delta T$, of $\sim 80 \mathrm{~K}$ (magnified in the inset). Combined with the surface morphology images in figure 2 , the local temperature evolution in an area of interest can be monitored. Here, the temperature evolution at the cracks initiated just above their threshold (figure 3(c), the specimen with $10^{5}$ pulses) is reported, through the image mapping illustrated in figure 5.

3.2.2. Transient temperature $(\Delta T)$ evolution. The long-term surface temperature evolution of sample IG\#4 is summarized in figure 6. The temperature spikes in the pyrometer signal shown in figures 4 and 6(a) were always observed when the laser was firing during the experiments. The reason is that the pyrometer occasionally captured a portion of the temperature excursion, giving rise to a range of temperature spikes. However, the bottom points, as indicated by the red line, reflected the real base surface temperature of the target. This was assured by the fact that the pyrometer reading quickly recovered to the red line level after terminating the laser firing. Furthermore, the plasma source $I-V$ characteristics and plasma parameters were continuously monitored during the experiments, precluding any plasma oscillations that could induce such unphysical temperature spikes. Therefore, stable base surface temperatures could be confirmed during the experiments. On the other hand, the IR-cam sampled every 5000 pulses (i.e. $500 \mathrm{~s}$ ) to trace $\Delta T$. Figure $6(b)$ displays the raw data (after subtracting the background) in terms of intensity (counts). Clearly, both the base and peak intensity gradually increase with pulse numbers. Since the base surface temperature was stable, the increasing base surface intensity therefore reflects the increasing emissivity of the target due to progressive surface roughening (figure 2). To correct for this, in figure $6(c)$, the emissivity is constantly adjusted such that the resulting base surface temperature matches that measured by the pyrometer. The corresponding emissivity adjustment $\Delta \varepsilon$ (see the definition of $\Delta \varepsilon$ in appendix A) is plotted in figure $6(d)$. To justify this procedure, the emissivity automatically determined by the pyrometer, but at a different wavelength, is shown in the right $y$-axis of figure $6(d)$. The similar 

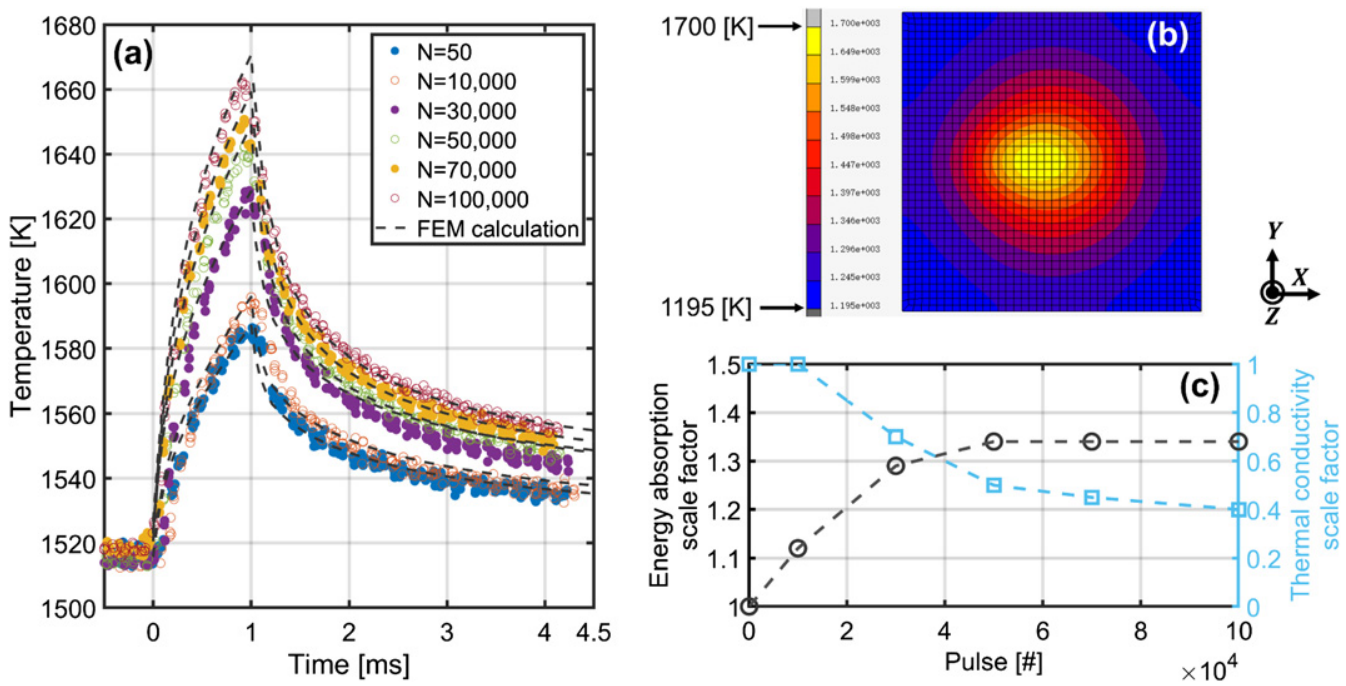

Figure 8. FEM analyses of specimen IG\#4. (a) The magnified transient temperature profiles at the indicated pulse numbers and the optimized FEM simulations. (b) The 3D FEM model, mesh and peak temperature distribution at $N=50$. The shift between the laser spot and the plasma beam center is visible in the asymmetry. $(c)$ The energy absorption and thermal conductivity evolution.

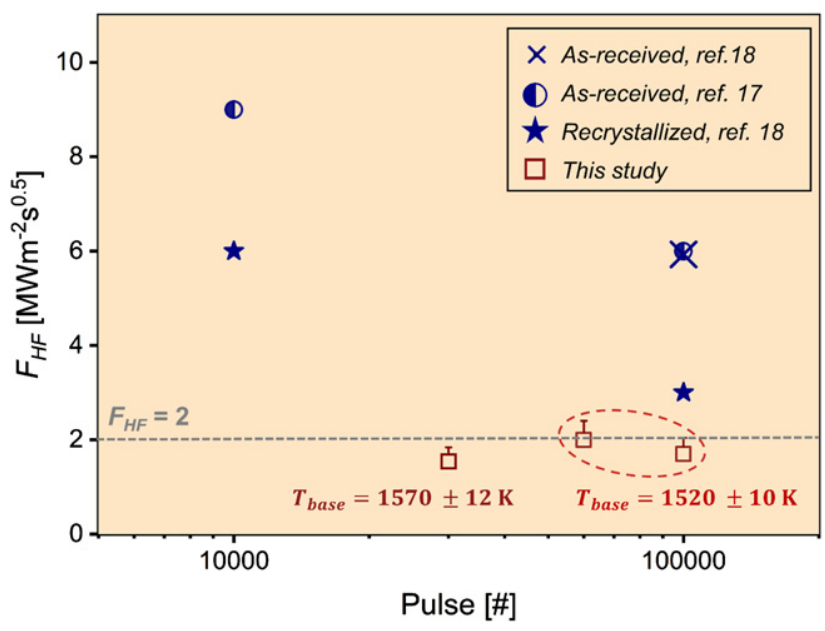

Figure 9. Crack initiation heat flux factor $F_{\mathrm{HF}}$ threshold of pure tungsten exposed to ELM-like transient heating. The referred results have a different base surface temperature $(973 \mathrm{~K}$ ) and material grades. See the discussion in the text.

emissivity evolution trend gives confidence in the reliability of the above exercise. Thereafter, the peak surface temperature in figure $6(c)$, and consequently the $\Delta T$ evolution in figure 7 were obtained. The same analyses were repeated for sample IG\#2 and IG\#3. Note that $\Delta T$ is approximately doubled at large pulse numbers for the specimens in figure 7. However, for specimens ' $\mathrm{IG} \# 5$ ' and ' $\mathrm{RX}$ ' in table 1, the increase of $\Delta T$ is less than $15 \mathrm{~K}$.

3.2.3. Finite element analyses. The increase of $\Delta T$ in figure 7 could be caused by: (i) increased laser power absorption (ii) decreased thermal conductivity of the target, or (iii) a combination of (i) and (ii). FEM simulations are performed next to disentangle these two effects.

A 3D thermal FEM model was constructed to simulate the measured temperature profiles in figure $8(a)$ using

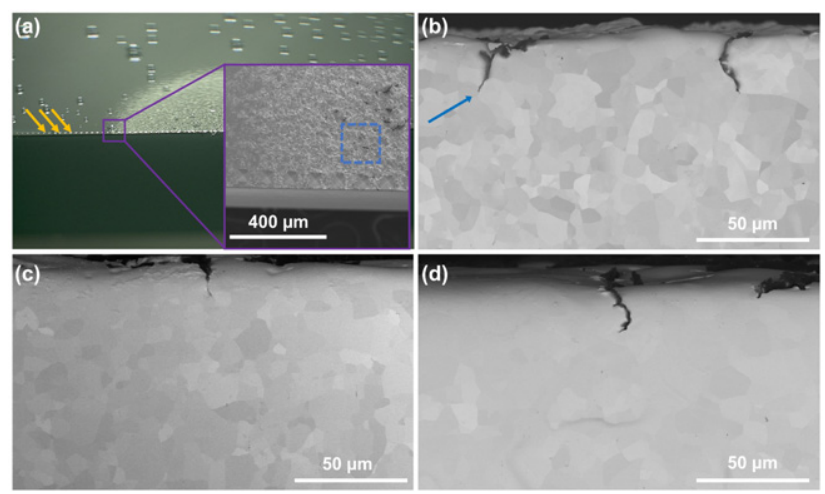

Figure 10. Cross-section micrographs near the cracks which were likely initiated just above the $F_{\mathrm{HF}}$ threshold. (a) An intermediate preparation step of sample IG\#2. A cross-section plane of the highlighted blue box in the inset is displayed in (b). Similarly, $(c)$ and $(d)$ refer to the blue box of sample IG\#3 and IG\#4 in figure 3, respectively.

MSC.Marc/Mentat ${ }^{\circledR}$. The FEM model, figure $8(b)$, consists of $\sim 17500$ eight-node cubic finite elements. The temperature-dependent thermal conductivity and heat capacity of tungsten were taken from [40, 41], respectively. As for boundary conditions, first, a steady-state Gaussian heat flux profile (10 mm FWHM) was applied on the top surface. The bottom nodes were prescribed with a uniform temperature such that the simulated top surface temperature matched the pyrometer measurement. After reaching thermal equilibrium, a transient Gaussian heat flux profile of $1 \mathrm{~ms}$ duration, mimicking the laser pulses, was applied to the top surface of the target. Its location and spatial distribution were obtained from the IR-cam. As noticeable in the asymmetry in figure $8(b)$, the shift between the laser spot and the plasma beam center was taken into account in the FEM simulation. 

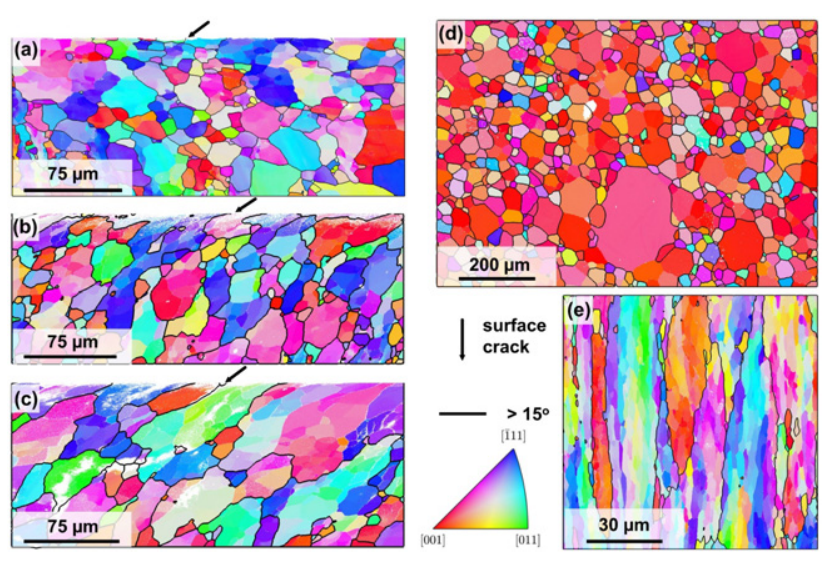

Figure 11. Out-of-plane inverse pole figure of the cross-section of (a) IG\#2, (b) IG\#3, (c) IG\#4, (d) recrystallized at $2000 \mathrm{~K}$ for $2 \mathrm{~h}$, and $(e)$ as-received state, respectively. SEM micrographs of the edge areas scanned in $(a)-(c)$ are, respectively, shown in figures $10(b)-(d)$. The reason for the severe warping of the EBSD maps in $(a)-(c)$ is explained in appendix B. The surface crack is specified by a black arrow and the HAGBs are outlined with black lines. The color key indicates the projected normal of the surface (analyzed by EBSD) in the crystal lattice reference frame.

The magnitude of the laser heat flux and the thermal conductivity of tungsten were manually adjusted to obtain an optimal match of the temperature profiles in figure $8(a)$. First, for the initial pulses $(N=50)$, an ideal thermal conductivity was assumed and the initial laser heat flux $q_{0}$ was determined by matching the simulated and measured temperature profiles. Thereafter, $q_{0}$ was up-scaled using the coefficients in the left $y$-axis of figure $8(c)$. This scaling accounts for the increasing laser energy absorption due to the increasing emissivity. Assuming that the absorption equals the emissivity (Kirchhoff's law of thermal emission [42]), the scale factors were calculated based on the emissivity evolution in figure $6(d)$. Then, the ideal thermal conductivity of the top 100 $\mu$ m tungsten layer was down-scaled accordingly to match the measured temperature profiles in figure $8(a)$. The thickness of this layer with a degraded thermal conductivity was motivated by cross-sectional micrographs in figure 15 . The corresponding thermal conductivity scaling factors are displayed in the right $y$-axis of figure $8(c)$. The thermal conductivity decreases to $\sim 40 \%$ of its ideal value at the end of the plasma exposure. Similar thermal conductivity degradation values were reported for tungsten under helium ion implantation/exposure [43-45]. Our results are therefore reasonable. The crack initiation heat fluxes (after taking into account the increasing laser absorption) are $49 \mathrm{MW} \mathrm{m}{ }^{-2}, 63 \mathrm{MW} \mathrm{m}^{-2}$, and $54 \mathrm{MW} \mathrm{m}^{-2}$ for specimen IG\#2, IG\#3, and IG\#4, respectively. Converting into a heat flux factor $F_{\mathrm{HF}}$, calculated as $q \times \sqrt{t}$, which is applicable for a square pulse in time [46], the resulting values are 1.5 $\mathrm{MW} \mathrm{m}^{-2} \mathrm{~s}^{0.5}, 2 \mathrm{MW} \mathrm{m}^{-2} \mathrm{~s}^{0.5}$, and $1.7 \mathrm{MW} \mathrm{m}^{-2} \mathrm{~s}^{0.5}$, respectively.

We found a heat flux factor $F_{\mathrm{HF}}$ of $\sim 2 \mathrm{MW} \mathrm{m}^{-2} \mathrm{~s}^{0.5}$ for fatigue crack initiation in this study. The asymmetric error bars come from the fact that the laser heat flux determined by FEM for the initial pulses is $\sim 15 \%$ lower than that calculated from the laser output power, assuming a laser energy absorption coefficient of 0.35 at $1064 \mathrm{~nm}$ [47]. Figure 9 also shows some related previous results from an electron beam facility. At a base surface temperature of $973 \mathrm{~K}$ and with $10^{5}$ pulses, the as-received tungsten with elongated grains oriented parallel to the heat-loaded surface has a crack initiation threshold of $\sim 6 \mathrm{MW} \mathrm{m} \mathrm{m}^{-2} \mathrm{~s}^{0.5}$ [17] whereas the recrystallized ITERgrade tungsten ( $1873 \mathrm{~K}$ for $1 \mathrm{~h}$ ) has a crack initiation threshold of $\sim 3 \mathrm{MW} \mathrm{m}^{-2} \mathrm{~s}^{0.5}$ [18]. Note that the different loading conditions (e.g. base surface temperature) and material grades strongly influence the crack initiation threshold. The comparison should not be overinterpreted. Figure 9 implies that recrystallization and a high base surface temperature have a detrimental impact on the crack initiation behavior of tungsten under repeated transient heat loads.

\subsection{Cross-section microstructural analysis}

Because the surfaces were strongly roughened by plastic deformation, EBSD scans were measured on the cross-section planes to acquire crystal orientation data and to identify the recrystallized zones. The cross-section micrographs are shown in figure 10. An intermediate cross-section preparation step of sample IG\#2 is shown in figure 10(a). The yellow arrows indicate the same indentation array as shown in figure $2(b)$. Magnified in the inset is the plasma modified surface with the crack initiation site highlighted, which is the same area as that in figure 3(a). A cross-section plane across the blue box, parallel to the indention array, is displayed in figure $10(b)$. The blue arrow indicates the furthest crack along the line of indention, which is the one that initiated just above the $F_{\mathrm{HF}}$ threshold. Similarly, figures $10(c)$ and $(d)$ display the cross-section morphologies of sample IG\#3 and sample IG\#4, respectively, near the highlighted areas in figure 3 .

Out-of-plane inverse pole figure maps of the cross-sections are shown in figure $11(a)-(c)$, respectively, with the surface crack indicated by an arrow. Because of the high tilt angle of the sample during EBSD measurements $\left(70^{\circ}\right.$ in this study), the cracks were difficult to visualize. Moreover, severe warping of the EBSD map is observed as caused by rounding off of the cross-section at the edge of the top surface, as explained in appendix B. Nevertheless, the crack locations were accurately identified in the EBSD maps by correlating the backscattered electron (BSE) images of a crack in its normal position and $70^{\circ}$ tilted position. One such example is illustrated in appendix B. The HAGBs $\left(>15^{\circ}\right)$ are outlined with black lines. To evaluate the recrystallized fractions of the plasma exposed samples, EBSD scans of the fully recrystallized state $(2000 \mathrm{~K}$ for $2 \mathrm{~h}$ ) and as-received state were also performed, displayed in figures $11(d)$ and $(e)$, respectively.

\section{Discussion}

The first three subsections aim to explain the results in figure 9, focusing on the mechanisms of recrystallization-mediated fracture. The last subsection elaborates on the implications of the results for the ITER tungsten divertor operation. 

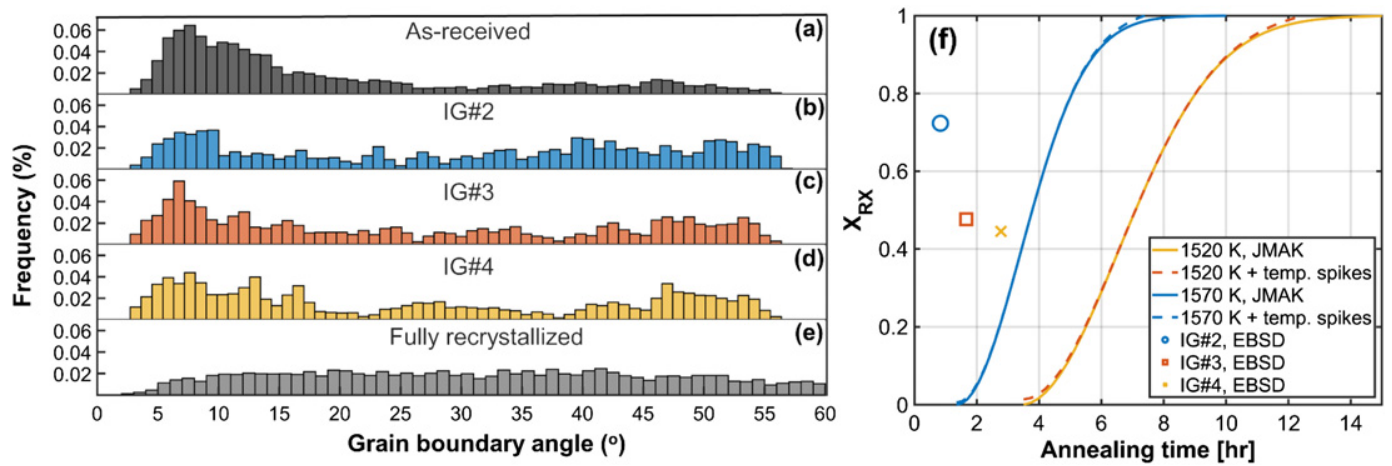

Figure 12. Grain boundary character distribution of $(a)$ as-received sample, $(b)$ IG\#2, $(c)$ IG\#3, $(d)$ IG\#4, and $(e)$ fully recrystallized sample. $(f)$ The measured and modeled recrystallized volume fraction.

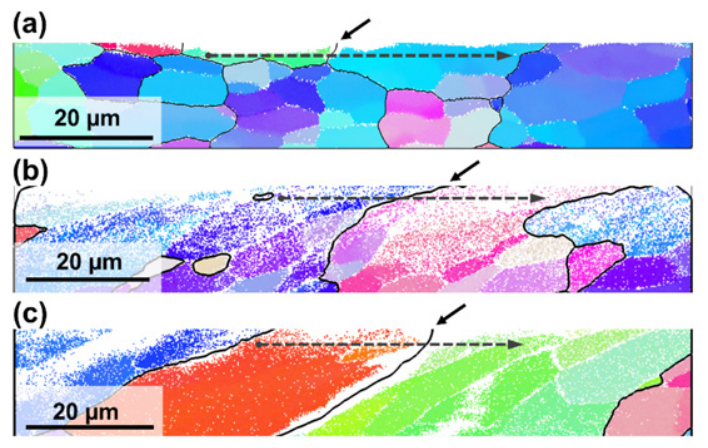

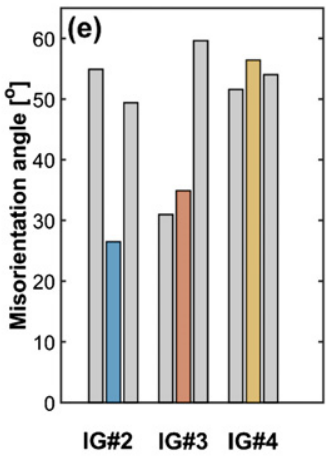

Figure 13. Grain boundary character of surface cracks. $(a)-(c)$ are magnified from figures $11(a)-(c)$, respectively. Each crack is indicated by a solid arrow and the same color key as that in figure 11 is adopted. $(d)$ The misorientation angle distribution along each indicated path across the crack in figures $11(a)-(c)$. (e) The misorientation angles of the left and right nearest HAGBs in addition to the fractured HAGBs The colored bars indicate the fractured HAGBs.

\subsection{Recrystallization kinetics}

The recrystallization kinetics are first considered. For the sake of simplicity, the Johnson-Mehl-Avrami-Kolmogorov (JMAK) model [48] was used:

$$
X_{\mathrm{RX}}=1-\exp \left(-B\left(t-t_{\text {inc }}\right)^{n}\right),
$$

where $X_{\mathrm{RX}}$ is the recrystallized volume fraction, $B$ describes thermal activation, $t$ is the annealing time, and $t_{\text {inc }}$ is the incubation time. Equation (1) was parameterized using the experimental work of Alfonso et al [49] on warm-rolled ITER-grade tungsten with a $90 \%$ thickness reduction (the coefficients are provided in appendix C). However, the tungsten-grade used in this study was forged and the deformation history (unrevealed by the manufacturer) was not necessarily the same. In order to calibrate it, the same tungsten grade was exposed to a steady-state hydrogen plasma in Magnum-PSI and the recrystallization kinetics were found to be adequately described by the above parameterized JMAK model [50]. Equation (1) will therefore serve as the baseline recrystallization kinetics in this study.

The recrystallized volume fraction of a plasma exposed sample was determined from the EBSD data as follows [38]:

$$
X_{\mathrm{RX}}=\frac{H A G B_{\mathrm{EXP}}-H A G B_{\mathrm{AR}}}{H A G B_{\mathrm{FRX}}-H A G B_{\mathrm{AR}}},
$$

where $\mathrm{HAGB}_{\mathrm{AR}}$ is the fraction of HAGBs in the as-received sample, HAGB ${ }_{\mathrm{FRX}}$ the fraction of HAGBs after full recrystallization $\left(2000 \mathrm{~K}\right.$ for $2 \mathrm{~h}$ ), and $\mathrm{HAGB}_{\mathrm{EXP}}$ the fraction of HAGB of an exposed sample. Figures 12(a)-(e) displays the grain boundary angle distribution of the five samples that are extracted from the data of the EBSD scans in figure 11. For the plasma exposed samples, an area of $100 \mu \mathrm{m} \times 100 \mu \mathrm{m}$ surrounding each surface crack was used to evaluate the HAGB fraction such that there were enough grains contained and the temperature variation within the analyzed region was negligible. Consequently, the $X_{\mathrm{RX}}$ values are summarized in figure $12(f)$, along with the JMAK calculations. It is observed that the experimentally measured $X_{\mathrm{RX}}$ is larger than the JMAK model prediction, in which no recrystallization (incubation phase) is suggested yet. To preclude the effect of the temperature spikes induced by transient heating on the recrystallization kinetics, each $\Delta T$ was approximated as a square wave with a height of the maximum $\Delta T$ and a width of $2 \mathrm{~ms}$ (it takes roughly $2 \mathrm{~ms}$ for a pulse to recover, see figure $8(a)$ ), which was superimposed on the steady-state base surface temperature history. As indicated by the dashed lines in figure $12(f)$, the effect is negligible. The results suggest that the JMAK model parameterized from continuous annealing data is not adequate to describe the recrystallization kinetics under transient heat loads where plastic strains are cyclically 


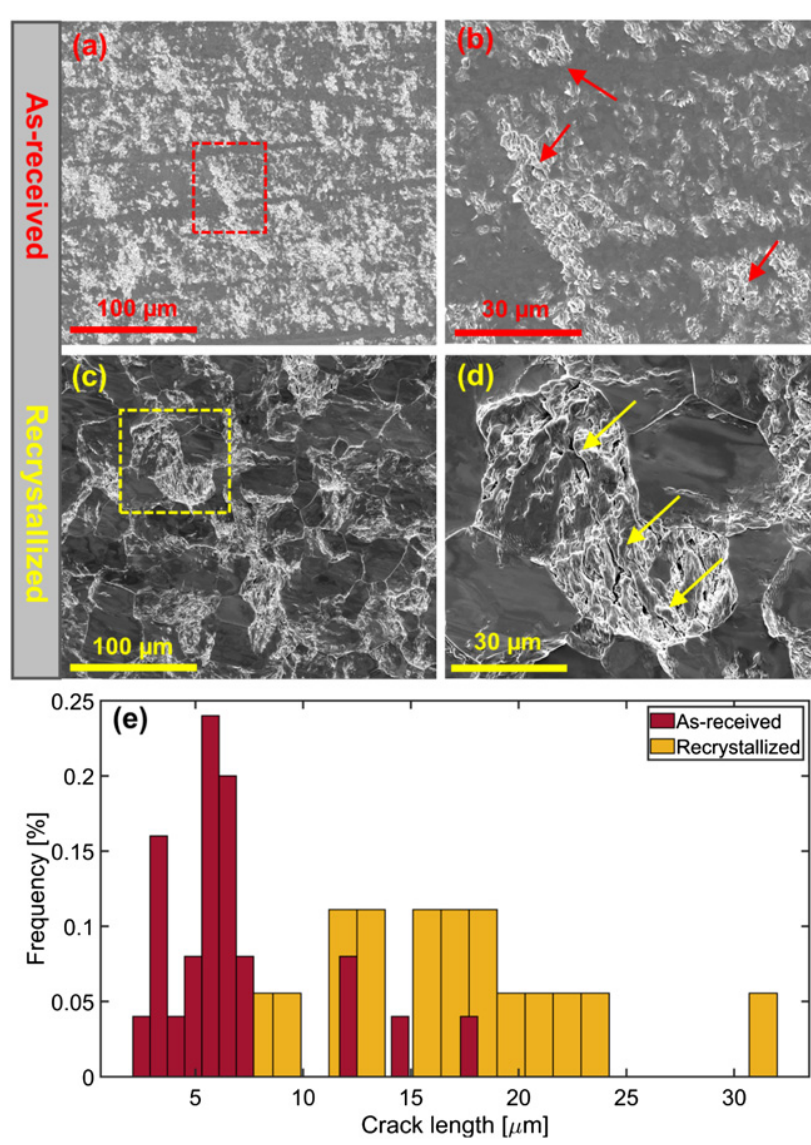

Figure 14. Surface morphology of as-received and recrystallized tungsten specimens exposed to $10^{5}$ pulses with a $\Delta T$ of $195 \pm 10 \mathrm{~K}$ at a base surface temperature of $1005 \pm 8 \mathrm{~K}$. The micrographs are taken from the laser spot center. (a) As-received tungsten with a highlighted area magnified in $(b)$. (c) Recrystallized tungsten with a highlighted area magnified in $(d)$. $(e)$ The corresponding crack length distribution. The arrows indicate surface protrusions and crack formation.

generated. Because the recrystallization nuclei originate at locations with a critical dislocation density [29], cyclic plastic straining may accelerate the recrystallization. Indeed, as will be shown later in figure 15(a), the maximum width of the recrystallized region in the cross-section is approximately the laser spot size ( $\sim 4 \mathrm{~mm}$ in the analyzed direction), suggesting that the laser heating induces the recrystallization. Numerical models that include evolving microstructures $[29,30]$ may help unravel the underlying mechanisms and lead to more accurate predictions.

\subsection{The role of HAGBs in fracture}

A salient feature of recrystallization is the increase of the HAGB fraction. Its impact on crack formation is therefore probed next. Figures 13(a)-(c) are magnified views from the surface cracks in figure 11. As can be seen, the cracks (indicated by arrows) coincide with the HAGBs, which are outlined with black lines. Quantitatively, figure 13(d) plots the misorientation angle distribution along the indicated paths in figures $13(a)-(c)$ with the fractured grain boundaries positioned at the origin. This allows to confirm the high angle character of the grain boundary along the crack path.

The preferential fracture of HAGBs can be explained based on the interactions between dislocations and grain boundaries. In polycrystals, dislocation arrangements generated by cyclic plastic straining (commonly referred to as persistent slip bands [51]) are impeded by grain boundaries, resulting in pile-ups and stress concentrations [52]. The stresses are (partially) relieved by the formation of surface protrusions and as well as dislocation transmissions across LAGBs [53, 54]. However, HAGBs are often impenetrable obstacles to dislocations, therefore promoting stress concentrations and intergranular fracture $[55,56]$. Interestingly, it is noted that there are intact HAGBs next to a cracked HAGB. Figure 13(e) plots the misorientation angle distribution of the left and right nearest HAGBs of the surface cracks with the colored bars representing the fractured HAGBs; no clear trend is observed, for example, a cracked HAGB does not always have the highest misorientation angle. This suggests that other grain boundary crystallographic parameters (uniquely described by five independent parameters [57]) such as grain boundary plane orientation could have played a role [58, 59] in crack formation. Nevertheless, HAGBs are clearly preferred sites for fracture.

\subsection{Mechanisms of recrystallization-mediated fracture}

To better understand the mechanisms of recrystallizationmediated crack initiation, two more specimens were tested. Recrystallized ('RX') and as-received ('AR') tungsten specimens with representative microstructures shown in figures $11(d)$ and $(e)$. These specimens were exposed to $10^{5}$ pulses with a $\Delta T$ of $195 \pm 10 \mathrm{~K}$ (the corresponding heat flux factor is $\sim 3.5 \mathrm{MW} \mathrm{m}^{-2} \mathrm{~s}^{0.5}$ ) at a base surface temperature of $1005 \pm 8 \mathrm{~K}$ (specimen 'RX' and 'IG\#5' in table 1). Because the base surface temperature is low enough in this case, the asreceived tungsten sample will not recrystallize after transient heating, thus better demonstrating the role of recrystallization in fracture. The micrographs from the laser spot center of both specimens are shown in figure 14. In the as-received tungsten specimen, the surface roughening is approximately uniform (the grooves in figure 14(a) are unintentional scratches); in contrast, the recrystallized tungsten specimen exhibits grain specific surface roughening where a heavily roughened region is typically surrounded by smooth grains (figure 14(c)). When zooming in, surface protrusions and small cracks are visible in both specimens, as indicated by the arrows. The general observation is that surface roughening is more heterogeneous and more extensive in the recrystallized specimen than in its as-received counterpart. This is explained as follows. First, in the as-received state, because of the low fraction of HAGBs (figure 12(a)), a grain is likely to be surrounded by LAGBs, in which dislocations can transmit. Conversely, in the recrystallized specimen, the probability that a grain is enclosed by HAGBs that constrain dislocation transmission to adjacent grains is high. This is also readily visible when comparing the microstructures in figures $11(d)$ and $(e)$. Consequently, out-of-plane deformation is promoted in the recrystallized 


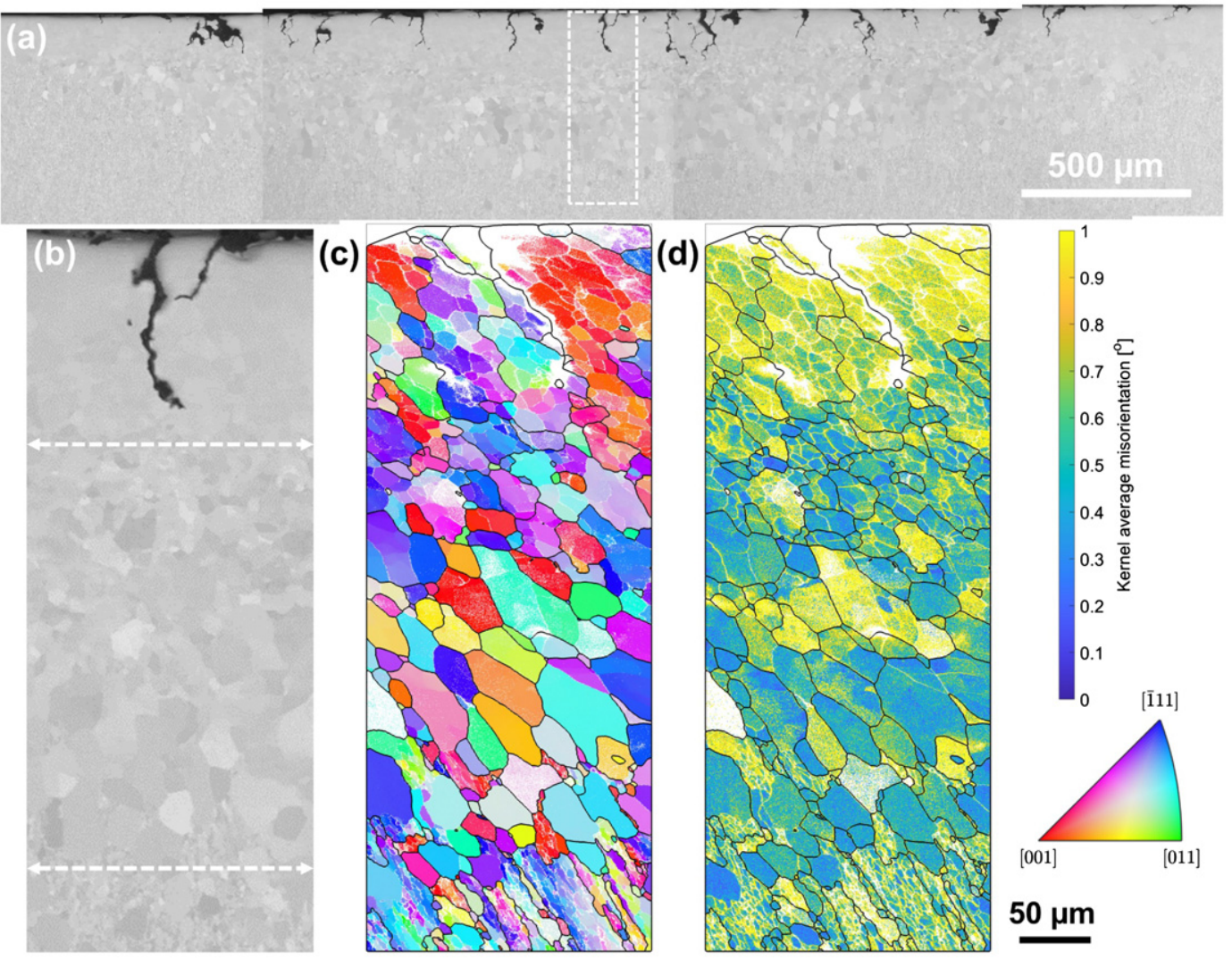

Figure 15. Cross-section analyses of sample IG\#4. (a) Secondary electron micrograph with the highlighted area magnified in $(b) .(c)$ Out-of-plane inverse pole figure of the same area and $(d)$ KAM distribution.

tungsten specimen, giving rise to pronounced surface protrusions when dislocations reach the surface. Moreover, the high dislocation density in the as-received specimen inhibits strain localization. For example, plastic deformation in clean crystals typically prevails on a limited number of slip systems $[60,61]$ while high dislocation densities activate multiple slip systems [62]. Finally, the recrystallized grains have a lower yield strength and therefore accumulate higher plastic strains than in the as-received specimen. Accordingly, the recrystallized grains possess a higher driving force for fatigue cracking $[22,23]$. In a later stage, cracks are likely to nucleate and form at or close to surface protrusions, as typically observed in metals [63-65]. In this way, it is expected that the recrystallized tungsten is more susceptible to fracture than its as-received counterpart. The corresponding crack length distribution in figure 14(e) supports the above explanation. The preferentially deformed grains may have specific crystal orientations with respect to the thermal stress loading direction, resulting in higher resolved shear stresses on the activated slip planes. Summarizing, upon recrystallization, a lower yield strength entails higher cyclic plastic strains, a higher fraction of HAGBs constrains the transfer of plastic strains at grain boundaries, and a lower amount of dislocations induces heterogeneous deformation. These are considered as three dominant mechanisms causing a reduced crack initiation threshold of recrystallized tungsten compared to its as-received counterpart.
The proposed mechanism applies to the as-received specimens exposed at high surface temperatures $(\sim 1550 \mathrm{~K})$ in figure 9 if recrystallization occurred before crack initiation. To demonstrate this condition, an EBSD scan around one central surface crack was performed in the depth direction of sample IG\#4. Figure 15(a) shows an overview of the cross-section with the EBSD scanned area highlighted. The cross-section is characterized by a trimodal grain size distribution (magnified and indicated in figure 15(b)). The bottom part has elongated grains and abundant LAGBs, resembling the as-received state (figure 11(e)). The middle part shows large grains with HAGBs, which is typical of the recrystallization microstructure under isothermal annealing (figure $11(d)$ ). Intriguingly, the top part shows a combination of the other two parts: a medium grain size and a moderate fraction of LAGBs and HAGBs, despite being the area at the highest temperature. The same trend was observed in sample IG\#2 and IG\#3 as shown in appendix D. Similar observations have been reported in reference [66]. Moreover, the top part is associated with a high dislocation density, as suggested by the first neighbor kernel average misorientation (KAM) map in figure $15(d)$; the KAM is linked to geometrically necessary dislocation density by Nye's tensor $[67,68]$. The above observations suggest that recrystallization first occurred in both the top part and the middle part because they have a similar grain size if we ignore the interior LAGBs in the top part grains. Since the top part was also subjected to additional cyclic plastic straining, the accu- 
mulation of dislocations led to near-surface grain refinement, as observed by the formation of a subgrain structure within the recrystallized grains, and the occurrence of fracture. In figure $15(d)$, some KAM hot spots are visible in the grains in the middle part. This seems to result from the recrystallization process as such KAM hot spots are also visible in the continuous annealed recrystallization sample (shown in appendix E). Based on the above analyses, the results in figure 9 suggest that: first, recrystallization decreases the fatigue crack formation and initiation $F_{\mathrm{HF}}$ threshold of tungsten; second, the high base surface temperatures under plasma exposure further decrease the crack initiation $F_{\mathrm{HF}}$ threshold by decreasing the yield strength and consequently accumulating more plastic strains.

It is worth discussing the influence of recrystallization on the thermo-mechanical performance of tungsten PFCs. As reviewed in the introduction section, there is a vivid debate in the literature on the role of recrystallization on the ductility of tungsten, which is related to the purity level and deformation history of the tested samples. However, it should be noted that the fracture behavior of metals under monotonic and cyclic loading are distinct [69, 70]. Therefore, ductility (e.g. strain-to-failure) obtained from a monotonicloading mechanical test, e.g. a uniaxial tensile test, cannot be used to predict its fatigue fracture behavior straightforwardly. Because the yield strength decreases and the HAGBs fraction increases after recrystallization, both promoting fatigue fracture, recrystallization may be detrimental to the plasma facing material (PFM) performance under repeated transient heat loads.

\subsection{Implications for the ITER tungsten PFCs}

The identified fatigue crack initiation energy fluence threshold in this study, $\sim 2 \mathrm{MW} \mathrm{m}^{-2} \mathrm{~s}^{0.5}$ (equivalently, $\sim 0.07 \mathrm{MJ} \mathrm{m}^{-2}$ for a $1 \mathrm{~ms}$ pulse), corresponds roughly to a $0.1 \%$ relative ELM size (defined as the ratio between the ELM outburst energy and the total stored energy of the core plasma, $\left.\frac{E_{\mathrm{ELM}}}{E_{\mathrm{plasma}}}\right)$ according to the latest empirical power scaling [8]. Such a low relative ELM size $(\sim 50$ times smaller than the natural ELM size) does not occur naturally in present tokamak experiments [1]. Therefore, if sufficient ELM mitigation cannot be achieved in ITER, surface cracking of a part of a MB may be inevitable.

The presence of surface cracks can affect current plasma-material interaction studies. For example, it may change the retention and sputtering behavior of tungsten. Regarding the structural integrity of the tungsten PFCs, the surface cracks might propagate deep into the material [10], entailing undesirable consequences. Furthermore, the surface cracking may reduce the steady-state power handling capability of tungsten. The new $16 \pm 2.5 \mathrm{MW} \mathrm{m}^{-2}$ criterion [7] builds on the assumption that cracking only appears when a surface layer of $2 \mathrm{~mm}$ is recrystallized which originates from a numerical study [5] employing some simplifying assumptions, e.g. on the cyclic plasticity behavior of tungsten. If some surface cracks are present, e.g. by some unmitigated ELMs, the above assumptions may no longer remain appropriate. This needs to be investigated in greater detail in future work.

\section{Conclusions and outlook}

This study represents a substantial effort to identify and rationalize the fatigue crack initiation heat flux factor threshold of tungsten under ELM-like heating loads. The major contributions are as follows:

(a) A new experimental method was developed to determine temperature-, wavelength-, and surface-dependent emissivity of tungsten. With this method, the $\Delta T$ induced by laser transient heating was found to nearly double. Emissivity measurements and FEM analyses revealed that the increasing $\Delta T$ originated from an increased laser power absorption $(\sim 35 \%)$ and a decreased thermal conductivity $(\sim 60 \%)$.

(b) The fatigue crack initiation threshold in terms of the heat flux factor of pure tungsten was identified to be $\sim 2 \mathrm{MW} \mathrm{m}^{-2} \mathrm{~s}^{0.5}$ (equivalently, $\sim 0.07 \mathrm{MJ} \mathrm{m}^{-2}$ for a $1 \mathrm{~ms}$ pulse) at a base surface temperature of $\sim 1550 \mathrm{~K}$ and with $10^{4}-10^{5}$ transient heating cycles. Note that this value is a loading parameter, which is different from the J-integral in fracture mechanics.

(c) It is observed that the recrystallization kinetics were accelerated near the surface where it was transiently loaded compared to the JMAK model prediction, and surface cracks preferentially formed at HAGBs. This was not the case for the region without laser loading, implying that the transient loading is driving the acceleration of the recrystallization process.

(d) Upon recrystallization, the yield strength decreases, entailing increased cyclic plastic strains. The HAGBs fraction increases, which constrains the transfer of plastic strains at grain boundaries. The overall dislocation density decreases which induces heterogeneous deformation. These three mechanisms explain the reduced crack initiation threshold of recrystallized tungsten compared to its as-received counterpart.

Based on these results, future studies are recommended to improve the understanding of the fracture behavior of tungsten under fusion relevant plasmas, which presents a much more severe risk of component failure compared to other plasmainduced modifications, e.g. helium fuzz and hydrogen blistering. Future complementary studies may extend the current study to a wider parameter space in a linear plasma generator or a fusion reactor. Laboratory-based mechanical tests to identify aspects such as fracture toughness [71, 72] and kinematic hardening behavior $[73,74]$ and to incorporate the effects of plasma species $[75,76]$ will also be very valuable. We also note that the sputtering and re-deposition of tungsten could influence the recrystallization and fracture behavior of the ITER MB. Based on SOLPS modelling [77], a surface layer of tungsten on the order of $1-1000 \mu \mathrm{m}$ could be eroded after $10^{6}$ ELMs. Therefore, future work in this respect is recommended. 


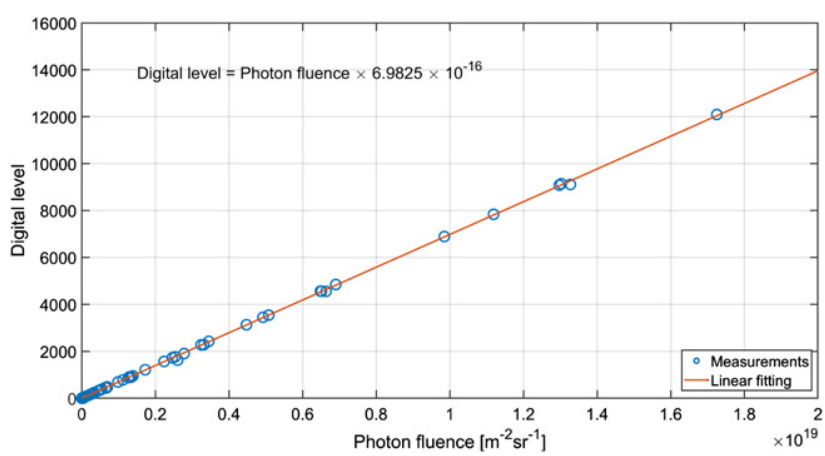

Figure A1. The IR-cam sensor sensitivity: digital level (counts) vs photon fluence. The spectral radiance and camera integration time in equation (A1) have been combined to yield the photon fluence. A good linear response is obtained.

\section{Acknowledgments}

We acknowledge the support of the Magnum-PSI Facility Team at DIFFER. The Magnum-PSI facility at DIFFER has been funded by the Netherlands Organisation for Scientific Research (NWO) and EURATOM. This work was supported by the European Commission and carried out within the framework of the Erasmus Mundus International Doctoral College in Fusion Science and Engineering (FUSION-DC). This work has been carried out within the framework of the EUROfusion Consortium and has received funding from the Euratom research and training programme 2014-2018 and 2019-2020 under Grant Agreement No. 633053. The views and opinions expressed herein do not necessarily reflect those of the European Commission.

\section{Appendix A. Thermographic analysis}

\section{A.1. Theory}

After subtraction of the background (e.g. due to infra-red light from the surroundings [78]), the following relationship applies [79]:

$$
N_{\text {grey }}=\tau \varepsilon\left(\lambda, T, R_{\mathrm{a}}\right) \underbrace{\frac{2 h c^{2}}{\lambda^{5}} \frac{1}{\mathrm{e}^{\frac{h c}{\lambda k_{\mathrm{B}} T}}-1}}_{\text {Planck'slaw }} t_{\text {expo }} S(\lambda),
$$

where $N_{\text {grey }}$ is the greyscale level recorded by the camera sensors and $\tau$ the transmission of the optical system $(0.145$ in our system). $\varepsilon\left(\lambda, T, R_{\mathrm{a}}\right)$ is the emissivity of tungsten, which is a function of wavelength $(\lambda)$, temperature $(T)$, and surface roughness $\left(R_{\mathrm{a}}\right)$. In Planck's law, $h$ is Planck's constant, $c$ is the speed of light in a vacuum, and $k_{\mathrm{B}}$ is Boltzmann's constant. $t_{\text {expo }}$ is the exposure time of the camera ( $200 \mu$ s in this study) and $S(\lambda)$ is the sensor sensitivity at wavelength $\lambda$. By calibration to a blackbody radiation source, for which $\varepsilon\left(\lambda, T, R_{\mathrm{a}}\right)=$ $1, S(\lambda)$ has been established for the spectral range of the used IR-cam, as shown in figure A1.

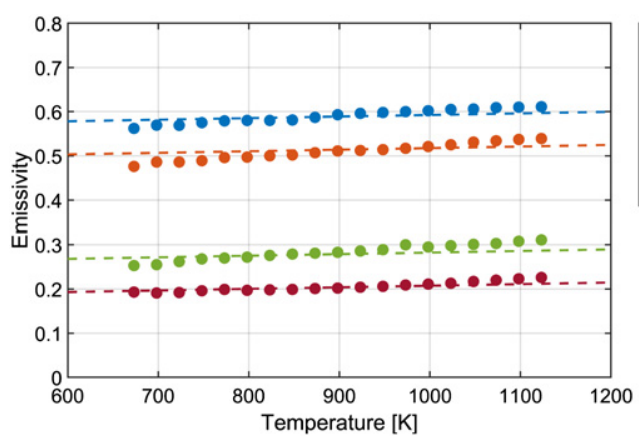
-Eq. (3), $\Delta \epsilon=0.385$ Damaged W\#1 Eq. (3), $\Delta \epsilon=0.3$ . Polished $w$ -

Figure A2. The measured emissivity of ITER-grade W from [82] and the calculated emissivity using equation (A3) with the corresponding emissivity offset $\Delta \varepsilon$.

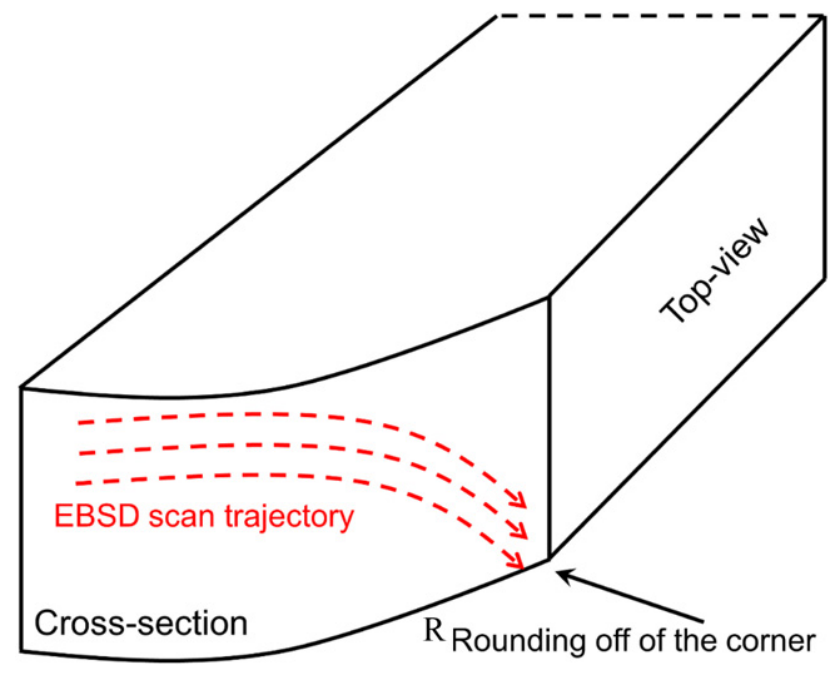

Figure B1. Sketch of the warping of the EBSD image due to rounding off of the specimen edge.

\section{A.2. Emissivity of tungsten}

$\varepsilon\left(\lambda, T, R_{\mathrm{a}}\right)$ of tungsten is required to utilize equation (A1). Based on the measurements of De Vos [80] on annealed tungsten ribbon (with a certain $R_{\mathrm{a}}$ value that has not been reported), the following expression derived by Sergienko [81] matches the experimental data $(\lambda>0.8 \mu \mathrm{m})$ within $2 \%$ error:

$$
\varepsilon(\lambda, T)=\varepsilon_{0}(\lambda)+\varepsilon_{1}(\lambda) T,
$$

in which $\varepsilon_{0}(\lambda)=0.4205\left(\lambda \frac{1.88949 \lambda^{3}+0.24191}{\lambda^{3}+1.90197}\right)^{-1}, \quad \varepsilon_{1}(\lambda)=$ $5.55537 \times 10^{-5}+1.777171 \times 10^{-6} \varepsilon_{0}(\lambda)-8.43353 \times$ $10^{-4} \varepsilon_{0}(\lambda)^{2}+9.82596 \times 10^{-4} \varepsilon_{0}(\lambda)^{3}$ with the wavelength $\lambda$ expressed in $\mu \mathrm{m}$ and temperature $T$ in kelvin.

$\varepsilon\left(\lambda, T, R_{\mathrm{a}}\right)$ is known to increase with the surface roughness $R_{\mathrm{a}}$ but no quantitative description exists so far. Here, we propose an experimental approach to address this. $R_{\mathrm{a}}$ does not alter the temperature-dependence of $\varepsilon\left(\lambda, T, R_{\mathrm{a}}\right)$ at a given wavelength $\lambda$, as shown in figure A2, where the emissivity of ITER-grade tungsten is shown for 4 increasing $R_{\mathrm{a}}$ levels in the wavelength range of $1.6 \mu \mathrm{m}$ to $2.1 \mu \mathrm{m}$, as measured by Gaspar 

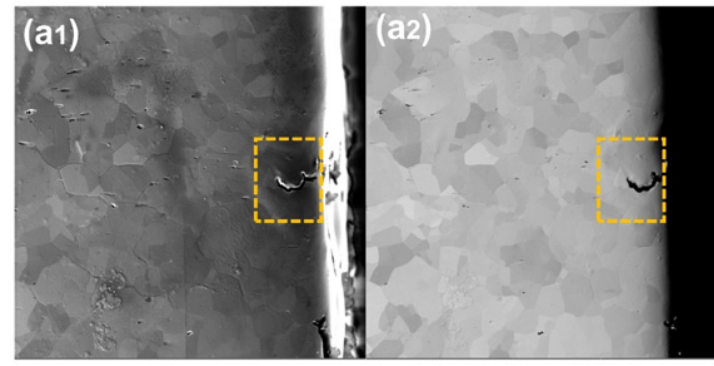

\section{(c)}
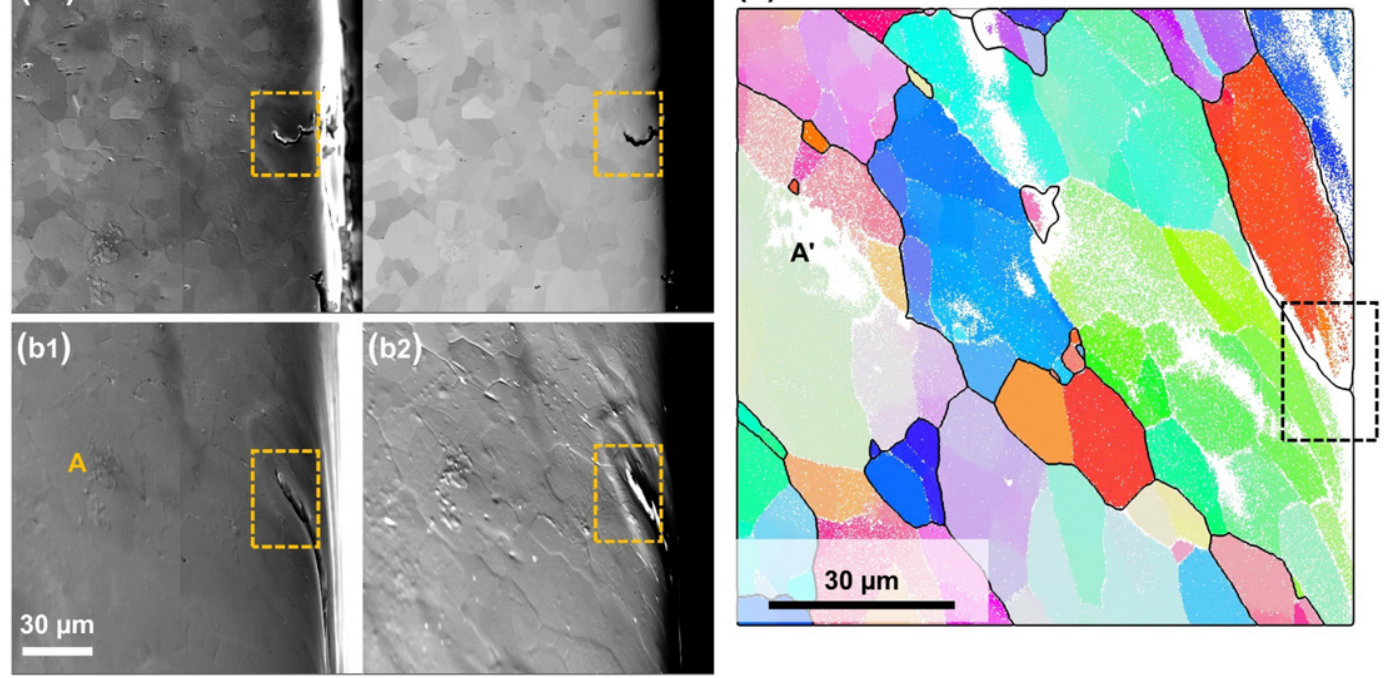

Figure B2. SEM images of the studied surface crack of sample IG\#4 in its $(a)$ normal position, $(b)$ tilted position, and $(c)$ the EBSD image. SEM and EBSD images are obtained at the same sample tilting position.

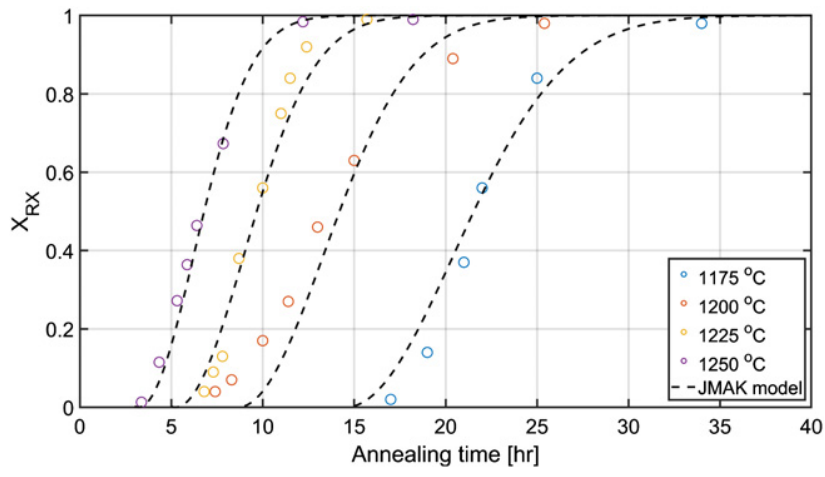

Figure C1. Measurements from [49] and calculations using equations $(\mathrm{C} 1)-(\mathrm{C} 3) . X_{\mathrm{RX}}$ is the recrystallized volume fraction.

et al [82]. Clearly, the emissivity increases with $R_{\mathrm{a}}$ (from polished tungsten to damaged tungsten), but the slope of the measurements is approximately the same. Moreover, equation (A2) (averaged over 1.6-2.1 $\mu \mathrm{m}$ ) matches the emissivity of polished W reasonably well, where the slight mismatch may be caused by the measurement uncertainties. Therefore, we introduce an offset factor $\Delta \varepsilon\left(R_{\mathrm{a}}\right)$ in equation (A2) to account for the dependence of the emissivity on surface roughness $R_{\mathrm{a}}$, such that:

$$
\varepsilon\left(\lambda, T, R_{\mathrm{a}}\right)=\underbrace{\varepsilon_{0}(\lambda)+\varepsilon_{1}(\lambda) T}_{\text {equation }(\mathrm{A} 2)}+\Delta \varepsilon\left(R_{\mathrm{a}}\right) .
$$

By assigning a proper value for the offset $\Delta \varepsilon$, in figure A2, the different measurements can be described adequately. If we can determine $\Delta \varepsilon$ for an arbitrary tungsten surface, its emissivity $\varepsilon\left(\lambda, T, R_{\mathrm{a}}\right)$ will be obtained. Combining equations (A1) and (A3), the offset $\Delta \varepsilon$ can be acquired by measuring the temperature at a pixel within the view field of the IR-cam using an emissivity free method. In this study, a multi-wavelength pyrometer served for this purpose.

\section{Appendix B. Identifying a crack location in an EBSD image}

First, the reason for the severe warping of the EBSD image is sketched in figure B1. This is caused by rounding off of the cross-section close to the top-view surface during grinding and polishing, and particularly the electro-polishing required for EBSD.

Second, secondary electron (SE) and backscattered electron (BSE) images of the furthest crack along the indents of sample IG\#4 are shown in figures B2(a1) and (a2), respectively. After tilting $70^{\circ}$ to the EBSD configuration, (b) displays the same crack as in $(a)$, which is also highlighted in $(c)$. This is achieved by first checking the EBSD image quality, as the crack is not indexed (white pixels). Second, some surface dirt is also not indexed, e.g. the area labeled with A. By comparing the relative locations of such features, the crack position is confirmed. Finally, some grains with well-defined shapes are also used as reference points to map figures $(b)$ and $(c)$.

\section{Appendix C. JMAK model parametrization}

To the data in [49], the following JMAK model expression has been fitted with an adequate agreement:

$$
X_{\mathrm{RX}}=1-\exp \left(-B\left(t-t_{\mathrm{inc}}\right)^{2}\right),
$$

in which,

$$
\begin{gathered}
B=\mathrm{e}^{-22.98} \times \mathrm{e}^{\left(\frac{3.28 \times 10^{5}}{R T}\right)}, \\
t_{\text {inc }}=\mathrm{e}^{-27.97} \times \mathrm{e}^{\left(\frac{3.69 \times 10^{5}}{R T}\right)},
\end{gathered}
$$

where $R$ is the universal gas constant $\left(8.3145 \mathrm{~J} \cdot \mathrm{mol}^{-1} \cdot \mathrm{K}^{-1}\right)$ and $T$ is the annealing temperature in kelvin. The results are plotted in figure $\mathrm{C} 1$. 

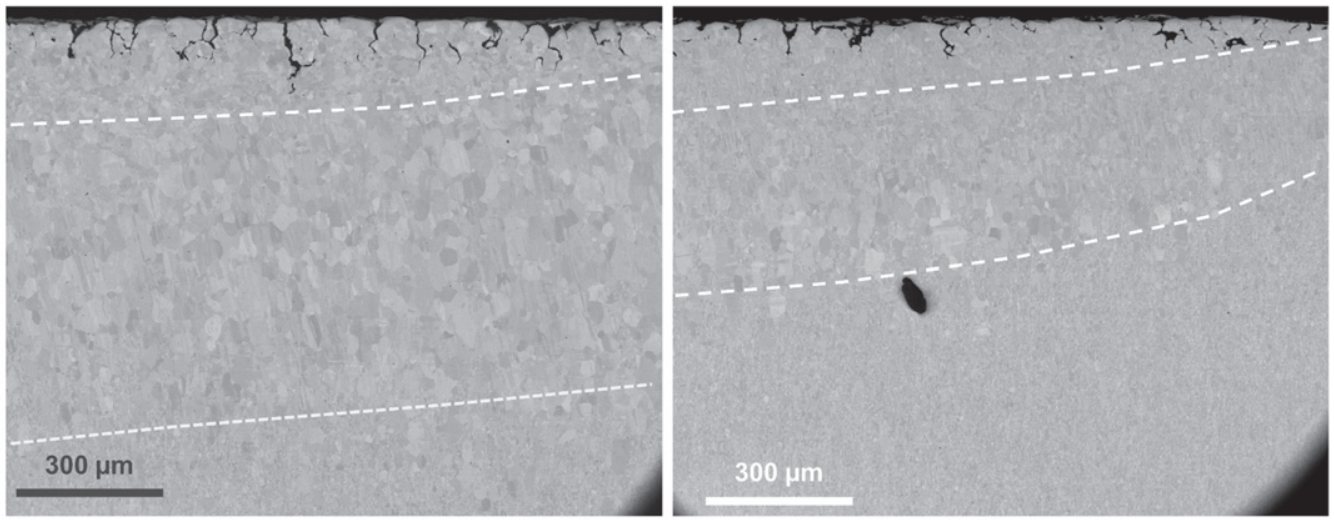

Figure D1. Cross-section overview of sample IG\#2 (left) and IG\#3 (right), displaying a trimodal grain size distribution.

(a)

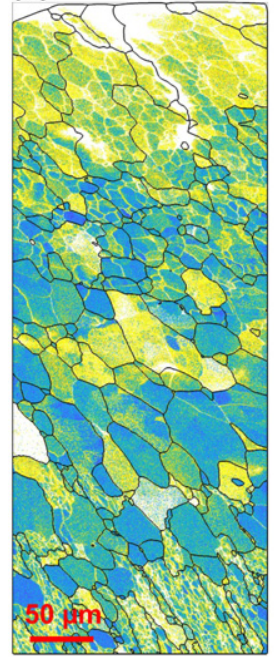

(b)

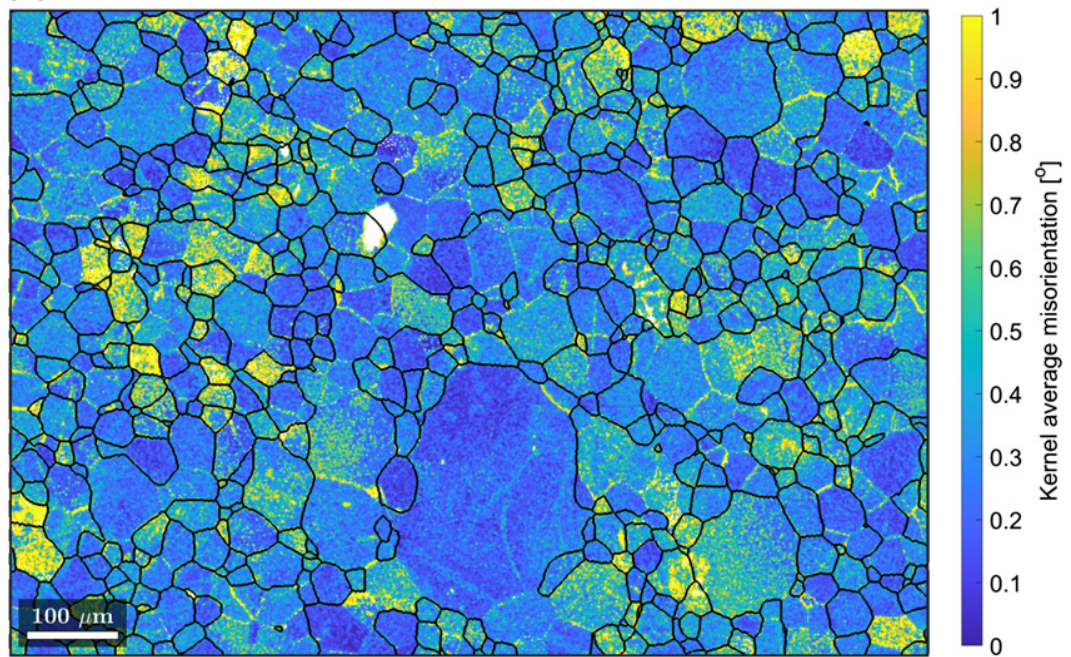

Figure E1. KAM distribution in tungsten samples recrystallized in $(a)$ Magnum-PSI and $(b)$ a vacuum oven.

\section{Appendix D. Trimodal grain size distribution on the cross-section}

Cross-section micrographs of sample IG\#2 and IG\#3 near the center. The dashed lines denote the region with different grain sizes (figure D1).

\section{Appendix E. KAM distribution in recrystallized tungsten samples}

KAM distribution in tungsten samples exposed in MagnumPSI and continuously annealed in a conventional vacuum oven. Clearly, KAM hot spots appear in the purely recrystallized regions of both specimens (figure E1).

\section{ORCID iDs}

T.W. Morgan (i) https://orcid.org/0000-0002-5066-015X Th. Loewenhoff (D) https://orcid.org/0000-0001-7273-4327 J.P.M. Hoefnagels (D) https://orcid.org/0000-0001-8359-7575
J.A.W. van Dommelen (D) https://orcid.org/0000-0003-40290308

M. Wirtz (D) https://orcid.org/0000-0002-1857-688X

G. De Temmerman (iD https://orcid.org/0000-0002-4173-0961

\section{References}

[1] Pitts R.A. et al 2019 Nucl. Mater. Energy 20100696

[2] Hirai T. et al 2014 Phys. Scr. T159 014006

[3] Hirai T. et al 2015 J. Nucl. Mater. 4631248

[4] Morgan T.W., Balden M., Schwarz-Selinger T., Li Y., Loewenhoff T.H., Wirtz M., Brezinsek S. and De Temmerman G. 2020 Phys. Scr. T171 014065

[5] Li M. and You J.-H. 2015 Fusion Eng. Des. 1011

[6] Alfonso A., Juul Jensen D., Luo G.-N. and Pantleon W. 2015 Fusion Eng. Des. 98-99 1924

[7] De Temmerman G., Hirai T. and Pitts R.A. 2018 Plasma Phys. Control. Fusion 60044018

[8] Eich T., Sieglin B., Thornton A.J., Faitsch M., Kirk A., Herrmann A. and Suttrop W. 2017 Nucl. Mater. Energy 12 84

[9] Leonard A.W. 2014 Phys. Plasmas 21090501

[10] Li Y. et al 2020 Nucl. Fusion 60046029 
[11] Chen Z. et al 2020 Nucl. Fusion 60046020

[12] Loewenhoff T., Antusch S., Pintsuk G., Rieth M. and Wirtz M. 2019 Nucl. Mater. Energy 20100680

[13] Wirtz M., Kreter A., Linke J., Loewenhoff T., Pintsuk G., Sergienko G., Steudel I., Unterberg B. and Wessel E. 2017 Phys. Scr. T170 014066

[14] Panayotis S., Hirai T., Barabash V., Amzallag C., Escourbiac F., Durocher A., Komarov V., Martinez J.M. and Merola M. 2017 Fusion Eng. Des. 125256

[15] Wirtz M. et al 2015 Nucl. Fusion 55123017

[16] Loewenhoff T. et al 2015 Nucl. Fusion $\mathbf{5 5} 123004$

[17] Loewenhoff T., Linke J., Pintsuk G. and Thomser C. 2012 Fusion Eng. Des. 871201

[18] Wirtz M., Linke J., Loewenhoff T., Pintsuk G. and Uytdenhouwen I. 2017 Nucl. Mater. Energy 12148

[19] Ren C., Fang Z.Z., Xu L., Ligda J.P., Paramore J.D. and Butler B.G. 2019 Acta Mater. 162202

[20] Wirtz M., Cempura G., Linke J., Pintsuk G. and Uytdenhouwen I. 2013 Fusion Eng. Des. 881768

[21] Shah V., van Dommelen J.A.W., Altstadt E., Das A. and Geers M.G.D. 2020 J. Nucl. Mater. 541152416

[22] Manson S.S. 1953 Behavior of Materials under Conditions of Thermal Stress (United States: National Advisory Committee for Aeronautics)

[23] Coffin L.F. Jr 1954 Trans. Am. Soc. Mech. Eng. 76 931-50

[24] Durif A., Richou M., Kermouche G., Lenci M. and Bergheau J.-M. 2019 Fusion Eng. Des. 138247

[25] Guo W., Cheng L., De Temmerman G., Yuan Y. and Lu G.-H. 2018 Nucl. Fusion $\mathbf{5 8} 106011$

[26] Song K., Thompson M., De Temmerman G. and Corr C.S. 2019 Nucl. Fusion $\mathbf{5 9} 096031$

[27] Alfonso A., Juul Jensen D., Luo G.-N. and Pantleon W. 2014 J. Nucl. Mater. $\mathbf{4 5 5} 591$

[28] Richou M., Durif A., Lenci M., Mondon M., Minissale M., Gallais L., Kermouche G. and De Temmerman G. $2020 \mathrm{~J}$. Nucl. Mater. $\mathbf{5 4 2} 152418$

[29] Bernard P., Bag S., Huang K. and Logé R. E. 2011 Mater. Sci. Eng. A $\mathbf{5 2 8} 7357$

[30] Mannheim A., van Dommelen J.A.W. and Geers M.G.D. 2018 Mech. Mater. 12343

[31] Ciulik J. and Taleff E.M. 2009 Scr. Mater. 61895

[32] Omori T., Kusama T., Kawata S., Ohnuma I., Sutou Y., Araki Y., Ishida K. and Kainuma R. 2013 Science 3411500

[33] Shah V., van Maris M.P.F.H.L., van Dommelen J.A.W. and Geers M.G.D. 2020 Nucl. Mater. Energy 22100716

[34] van Eck H.J.N. et al 2019 Fusion Eng. Des. 14226

[35] van der Meiden H.J. et al 2012 Rev. Sci. Instrum. 83123505

[36] van der Meiden H.J., Vernimmen J.W.M., Bystrov K., Jesko K., Kantor M.Y., De Temmerman G. and Morgan T.W. 2016 Appl. Phys. Lett. 109261102

[37] Bachmann F., Hielscher R. and Schaeben H. 2010 Solid State Phenom. 16063

[38] Jazaeri H. and Humphreys F.J. 2004 J. Microsc. 213241

[39] Humphreys F.J. 2001 J. Mater. Sci. 363833

[40] Ho C.Y., Powell R.W. and Liley P.E. 1972 J. Phys. Chem. Ref. Data 1279

[41] White G.K. and Collocott S.J. 1984 J. Phys. Chem. Ref. Data 13 1251

[42] Robitaille P.-M. 2009 Prog. Phys. 4 3-13

[43] Hofmann F., Mason D.R., Eliason J.K., Maznev A.A., Nelson K.A. and Dudarev S.L. 2015 Sci. Rep. 516042

[44] Qu S. et al 2017 J. Nucl. Mater. 484382

[45] Kajita S., Yagi T., Kobayashi K., Tokitani M. and Ohno N. 2016 Results Phys. 6877

[46] Hirai T. and Pintsuk G. 2007 Fusion Eng. Des. 82389

[47] Maeji T. et al 2017 Fusion Eng. Des. 124287
[48] Humphreys F. and Hatherly M. 2004 Recrystallization and Related Annealing Phenomena (Amsterdam: Elsevier)

[49] Lopez A.A. 2015 Thermal Stability of Warm-Rolled Tungsten phd thesis (Denmark: Technical University of Denmark)

[50] Shah V., Beune J.T.S., Li Y., Loewenhoff T., Wirtz M., Morgan T.W. and van Dommelen J.A.W. 2021 J. Nucl. Mater. 545 152748

[51] Differt K., Esmann U. and Mughrabi H. 1986 Phil. Mag. A 54 237

[52] Essmann U., Gösele U. and Mughrabi H. 1981 Phil. Mag. A 44 405

[53] Kobayashi S., Kamata A. and Watanabe T. 2009 Scr. Mater. 61 1032

[54] Zhang Z.F., Wang Z.G. and Li S.X. 1998 Fatigue Fract. Eng. Mater. Struct. 21 1307-16

[55] Zhang Z.F. and Wang Z.G. 2000 Mater. Sci. Eng. A 284 285-91

[56] Sangid M.D., Maier H.J. and Sehitoglu H. 2011 Int. J. Plast. 27 801

[57] Rohrer G.S., Saylor D.M., Dasher B.E., Adams B.L., Rollett A.D. and Wynblatt P. 2004 Z. Metall. 95197

[58] Kim C.-S., Rollett A.D. and Rohrer G.S. 2006 Scr. Mater. 54 1005

[59] Zhai T., Wilkinson A.J. and Martin J.W. 2000 Acta Mater. 48 4917

[60] Uchic M.D., Dimiduk D.M., Florando J.N. and Nix W.D. 2004 Science 305986

[61] Du C., Maresca F., Geers M.G.D. and Hoefnagels J.P.M. 2018 Acta Mater. 146314

[62] He B.B., Hu B., Yen H.W., Cheng G.J., Wang Z.K., Luo H.W. and Huang M.X. 2017 Science 3571029

[63] Bao-Tong M. and Laird C. 1989 Acta Metall. 37325

[64] Antolovich S.D. and Armstrong R.W. 2014 Prog. Mater. Sci. 591

[65] Lavenstein S., Gu Y., Madisetti D. and El-Awady J.A. 2020 Science $\mathbf{3 7 0}$ eabb2690

[66] Loewenhoff T.W. 2012 Combined steady state and high cycle transient heat load simulation with the electron beam facility JUDITH $2 P h D$ Thesis (Germany: RWTH Aachen University)

[67] Nye J.F. 1953 Acta Metall. 1153

[68] Wilkinson A.J. and Randman D. 2010 Phil. Mag. 901159

[69] Pineau A., Benzerga A.A. and Pardoen T. 2016 Acta Mater. 107 424

[70] Pineau A., McDowell D.L., Busso E.P. and Antolovich S.D. 2016 Acta Mater. 107484

[71] Ast J., Schwiedrzik J.J., Wehrs J., Frey D., Polyakov M.N., Michler J. and Maeder X. 2018 Mater. Des. 152168

[72] Li B.-S., Marrow T.J., Roberts S.G. and Armstrong D.E.J. 2019 JOM 713378

[73] Chaboche J.L. 1991 Int. J. Plast. 7661

[74] Terentyev D., Dubinko A., Riesch J., Lebediev S., Volkov I. and Zhurkin E.E. 2020 Int. J. Refract. Hard Met. 86105094

[75] Das S., Armstrong D.E.J., Zayachuk Y., Liu W., Xu R. and Hofmann F. 2018 Scr. Mater. 146335

[76] Li Y. et al 2020 Nucl. Fusion 60086015

[77] Dux R., Loarte A., Angioni C., Coster D., Fable E. and Kallenbach A. 2017 Nucl. Mater. Energy 1228

[78] t Hoen M. 2014 Deuterium retention in radiation damaged tungsten exposed to high-flux plasma PhD Thesis (Netherlands: Delft University of Technology)

[79] Monier R., Thumerel F., Chapuis J., Soulié F. and Bordreuil C. 2017 Measurement 10172

[80] De Vos J.C. 1954 Physica 20690

[81] Sergienko G. 2020 Plasmaphysik (IEK-4), Institut für Energieund Klimaforschung, Germany private communication

[82] Gaspar J. et al 2019 Fusion Eng. Des. 149111328 